\title{
Interdependencies in the Energy-Bioenergy-Food Price Systems: A Cointegration Analysis
}

\author{
Pavel Ciaian and d'Artis Kancs
}

\section{EERI Research Paper Series No 06/2009}

ISSN: 2031-4892

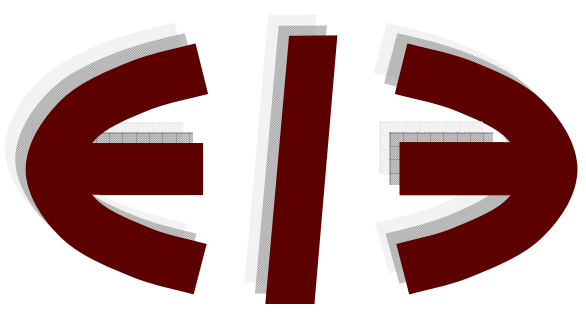

\section{EERI}

Economics and Econometrics Research Institute Avenue de Beaulieu 1160 Brussels

Belgium

Tel: +3222993523

Fax: +322 2993523

www.eeri.eu 


\title{
Interdependencies in the Energy-Bioenergy-Food Price Systems: A Cointegration Analysis*
}

\author{
Pavel Ciaian ${ }^{\dagger} \quad$ d'Artis Kancs ${ }^{\ddagger}$
}

December 2009

\begin{abstract}
The present paper studies the interdependencies between the energy, bioenergy and food prices. We develop a vertically integrated multi-input, multioutput model, which suggests two channels of price transmission: a direct biofuel channel and an indirect input channel. To test the theoretical hypothesis, we apply time-series analytical mechanisms to nine major traded agricultural commodity prices, including corn, wheat, rice, sugar, soybeans, cotton, banana, sorghum and tea, along with one weighted average world crude oil price. The data consists of 783 weekly observations extending from January 1994 to December 2006. The empirical findings confirm the theoretical hypothesis that the prices for crude oil and agricultural commodity are interdependent. Agricultural commodity prices are affected through the direct biofuel channel: an increase in oil price by 1 dollar/barrel increases the agricultural commodity prices between $0.10 \$$ /tonne and $1.50 \$ /$ tonne. Contrary to the theoretical predictions, the indirect input channel of price transmission is small and statistically insignificant.
\end{abstract}

Keywords: Energy, bioenergy, crude oil, prices, renewable fuels, cointegration. JEL classification: C14, C22, C51, Q11, Q13, Q42.

*The authors acknowledge helpful comments from Martijn Brons and Gerrit Cornelis van Kooten as well as EAERE conference participants in Amsterdam. The financial support from the FP7 project 'New Issues in Agricultural, Food and Bioenergy Trade' (AgFoodTrade), and the Federal Ministry's of Education projects APVV-0706-07, VEGA 10714/09 and KEGA K-08-004-00 is greatly acknowledged. The authors are solely responsible for the content of the paper. The views expressed are purely those of the authors and may not in any circumstances be regarded as stating an official position of the European Commission.

${ }^{\dagger}$ European Commission (DG Joint Research Centre), Catholic University of Leuven (LICOS), and Economics and Econometrics Research Institute (EERI). E-mail: pavel.ciaian@ec.europa.eu.

${ }^{\ddagger}$ European Commission (DG Joint Research Centre), Catholic University of Leuven, and and Economics and Econometrics Research Institute (EERI). Correspondence Address: European Commission, DG JRC, B-1049 Brussels, Belgium. E-mail: d'artis.kancs@ec.europa.eu. 


\section{Introduction}

In recent years the production of bioenergy has increased significantly around the world. The expansion of bioenergy was driven, among others, by rising energy prices, and environmental policies aimed at reducing harmful effects of conventional sources of energy on global climate changes. ${ }^{1}$ Bioenergy has a direct effect on agricultural sector, because it uses agricultural commodities as inputs, which are produced on a fixed area of agricultural land. ${ }^{2}$ It competes with food production for agricultural commodities, which creates an upward pressure on agricultural prices. Because of price inelastic food demand, and inelastic land supply, the price increase of agricultural commodities may be substantial. The positive price effect of bioenergy may be mitigated by two factors. First, new technological development may improve yields and lead to an offsetting effect in supply of agricultural commodities. Second, with rising agricultural profitability, unused fallow land may be brought into cultivation. However, because technological improvement is costly, and the fallow land brought into cultivation usually is less productive, these factors cannot fully offset the positive price effect of bioenergy (Huber 2007; Nielsen, Oleskowicz-Popiel and Al Seadi 2007).

The possibility that bioenergy support policies might have contributed to the recent food price increase has sparked a lively debate and controversy about the contribution of biofuels to the recent food commodity price developments particularly the impact of biofuels on the 2007-2008 food price rise. On the one hand, international organisations such as the World Bank (2008) and the IMF 2008 argue that biofuels were an important factor leading to higher food prices. According to the World Bank's study, up to 75 percent increase in food commodity prices could be attributed to the biofuels (Mitchell 2008). The IMF estimated that the increased demand for biofuels accounted for 70 percent of the increase in corn prices and 40 percent of the increase in soybean prices (Lipsky 2008). Similarly, also FAO (2008) and OECD (2009) argue that the expansion of biofuel production was a substantial factor leading to the recent food price increase.

On the other hand, the policy executives in the EU and US play down the importance of biofuels in explaining the recent food price developments. The USDA agrees that the demand for biofuels is having an impact on food commodity prices,

\footnotetext{
${ }^{1}$ Throughout the paper we use terms (fossil) energy, crude oil and fuel as synonyms.

${ }^{2}$ The main input in bioenergy production is biomass. Biomass covers a wide range of plant sources, including those that are used for fuel directly (e.g. fuelwood), and those that are processed into biofuels (corn, soy, sugarcane, sugar beet, rapeseed, wheat, etc.). Main biofuel products include ethanol (alcohol), biodiesel, and biogas. Main crops used for ethanol production include maize, sugar cane, sugar beet and wheat. Main crops used for biodiesel production are rapeseed, soy, and palm oil. Biogas can be produced either from biodegradable waste materials or from energy crops.
} 
but it is not a major factor. According to the USDA, only $3 \%$ of the $40 \%$ rise in global food prices can be attributed to biofuels production (USDA 2008). Similarly, European Commission (2008) acknowledges that the energy prices affect food commodity prices through the indirect input channel (by increasing the cost of inputs like nitrogen fertilisers and transport costs). However, the European Commission argues that the impact is likely very small: "The European Union currently uses less than 1 percent of its cereal production to make ethanol. This is a drop in the ocean. It uses two-thirds of its rapeseed crop to make biodiesel, but in fact European rapeseed production accounts for about 2 per cent of global oilseed demand. So this is not something to shake the markets" (European Commission 2008). Similarly, German government (Germany being Europe's largest biofuel producer) argues that other factors (e.g. changing eating habits in developing nations) are primarily to blame for the recent rising food prices rise and not biofuel production (Reuters 2008).

The simultaneous increase in price volatility on energy and agricultural commodity markets has generated also a growing number of scientific studies attempting to explain the linkages between fossil energy and agricultural prices. Two types of approaches have been followed in the literature. First, cointegration analysis were used to estimate the long-run relationship between the fuel price and agricultural prices (Campiche et al 2007; Yu et al 2006; Hameed and Arshad 2008; Imai et al 2008). The shortcomings of these reduced form studies are that they do not provide theoretical basis for deriving an estimable model, and they do not identify the channels of price transmission. Second, partial and general equilibrium models were developed to simulate the interdependencies between prices (Arndt 2008; Gardner (2007); de Gorter and Just 2008, 2009; Hayes et al 2009; Birur et al 2008; Tokgoz 2009). The disadvantage of this approach is that the simulated effects largely depend on the calibrated or arbitrary assumed price transmission elasticities. We are not aware of any work combining the theoretical underpinning with empirical evidence in a unified framework. This is the main purpose of this paper.

The objective of this paper is to investigate the interdependencies between the energy, bioenergy and agricultural markets both theoretically and empirically. Our theoretical model (section 2) builds on the models of Gardner (2007) and de Gorter and Just $(2008,2009)$, which develop a vertical integration model of ethanol, byproduct, and corn markets to analyse the welfare effects of corn production subsidies and ethanol subsidy in the US. In order to analyse two-way price interdependencies, we extend the existing models along several dimensions. First, we consider two (instead of one) agricultural commodities. Second, we consider price transmissions also through the input channel. Third, our model is not specific to the US, but is 
generally applicable for the world markets. Finally, we apply the model to analyse the interdependencies between fuel and agricultural commodity prices, but not to analyse the welfare effects of biofuel/agricultural policies.

Our empirical approach (section 3) is based on the cointegration analysis ( $\mathrm{Jo}$ hansen 1988; Johansen and Juselius 1990). We examine the existence of a long-run relationships between the crude oil and agricultural commodity prices by applying the error correction estimation procedure. In a first step, we test the ten price series for stationarity using the Augmented Dickey-Fuller and Phillips Perron tests. Based on the unit root test results, we then examine whether there exist cointegrating vectors among the nine agricultural commodity price series and crude oil. Finally, in order to identify a structural model and determine whether the estimated model is reasonable, we perform innovation accounting and causality tests on the estimated error-correction model. The Granger causality tests suggest long run unidirectional causality from oil price to agricultural commodity prices. However, the tests deny the presence of a similar relation in the opposite direction.

The paper has important policy implications, as it sheds light on the impact of biofuel subsidies on agricultural prices. According to FAO (2008) and OECD (2009), one of the main factors leading to recent food price increase was the expansion of biofuel production. However, the exact relationship between the energy, bioenergy and food price systems is little studied and understood yet (IMF 2008; von Braun 2008; World Bank 2008). Hence, our findings provide useful insights for understanding whether biofuels may exercise a long-run pressure on agricultural markets or whether it is a temporary phenomenon, and scientific support for shaping the bioenergy and food polices. Most governments in developed countries have introduced policies to promote bioenergy production and use. The findings of this paper may indirectly indicate what effect the bioenergy support polices may have on agricultural prices and thus potentially affecting agricultural production, food consumption and use of land resources.

\section{Theoretical framework}

\subsection{Previous models}

Several models have been developed for studying the effect of biofuels on agricultural markets. Gardner (2007) develops a vertical integration model of ethanol, by-product, and corn markets to analyse the welfare effects of corn and ethanol subsidies in the US. The main shortcoming of this model is that it does not consider 
the aggregate fuel market (fossil fuel and biofuels such as ethanol). Gardner assumes only market for ethanol (a downward sloping demand and an upward sloping supply of ethanol), which affects corn market through a derived demand for corn in ethanol production. This implies that fossil fuel and ethanol are assumed to be imperfect substitutes in consumption. The transmission between the fuel and corn prices depends on the assumptions about correlation of the fuel and ethanol prices.

De Gorter and Just $(2008,2009)$ develop a similar model to Gardner (2007) with one agricultural product (corn), ethanol market and by-product, and analyse the welfare effects of corn and ethanol subsidies in the US. They extend Gardner's model to aggregate fuel market, and consider perfect and imperfect substitutability in consumption between fossil fuel and ethanol. The price transmission between fuel and corn is effectuated through the demand for corn in ethanol production. The price transmission occurs, when the price for fuel is sufficiently high and/or when corn price is sufficiently low, so that ethanol production from corn is profitable relative to the profitability of non-ethanol use of corn. For low fuel and/or high corn prices, price transmission will not occur. In this case the production of ethanol from corn may not be competitive implying no ethanol production in equilibrium.

Similarly, Saitone et al (2008) focus on the ethanol and corn sectors in the US, and analyse price and income distribution effects of ethanol subsidies. However, they consider seed seller market power upstream from the agricultural sector, and buyer market power downstream from the farm in the corn-processing sector. Saitone et al show that market power has implications for transmission of ethanol expansion due to the crop subsidy. Market power in the downstream corn-processing sector causes a smaller increase in corn price due to the ethanol subsidy, while the upstream seed suppliers' market power has an ambiguous effect on the corn price, because market power in the seed sector induces offsetting effects on corn prices.

In all four models of Gardner (2007), de Gorter and Just (2008, 2009), and Saitone et al (2008) the transmission of prices from fuel to agricultural markets is effectuated only through the demand for agricultural commodity in biofuel production. There is no price transmission through the indirect input channel. However, in reality, fuel is an important input in agricultural production. Hence, changes in fuel price affect agricultural production costs and hence agricultural prices. Ignoring this effect may lead to upward biased estimates of biofuel expansion on agricultural prices. Second, all three models assume only one agricultural commodity. With multiple commodities the derived effects may change and fuel market may affect not only biomass crops, but also those commodities, which are not used in biofuel production.

The present study builds on models of Gardner (2007) and of de Gorter and Just 
(2008, 2009) and introduces two important extensions. First, we assume two agricultural commodities: one suitable for biofuel production (referred to as "biomass") ${ }^{3}$ and one not suitable for biofuel production (referred to as "food"). Second, we consider the transmission of prices also through the input channel. Both extensions improve the accuracy of model predictions. Compared to previous studies, also the scope of this paper is different. We do not focus on the US, but on the world biofuel market, and we use the model to analyse the interdependencies between fuel and agricultural commodity prices, instead of analysing the welfare effects of biofuel/agricultural policies.

\subsection{The model}

We consider a world market model of vertically integrated agricultural, biofuel, fossil fuel, by-product, and input markets (Figure 1). The representative farm can substitute between producing two agricultural commodities (biomass and food) using constant return to scale production functions of two substitutable inputs: fuel and other inputs (referred as to "land"). Agricultural output can be supplied to food market and to biofuel market. We assume fixed Leontief coefficient transformation function of biomass into biofuel and by-product from biofuel production. Further, we assume a downward sloping demand for food and by-product, and an upward sloping supply curve for land. The aggregate fuel supply is sum of biofuel and fossil fuel supplies. The aggregate fuel demand is sum of agricultural and non-agricultural fuel demand. The fossil fuel supply (non-agricultural fuel demand) is given by upward (downward) sloping functions of prices.

The representative agricultural farm maximises its profits according to: $\Pi=$ $\sum_{i} p^{i} Q^{i}\left(N^{i}, K^{i}\right)-w N^{i}-r K^{i}$, which implies the following equilibrium conditions:

$$
\begin{aligned}
p^{i} \frac{\partial Q^{i}}{\partial N^{i}} & =w \\
\text { for } i & =A B, A N \\
p^{i} \frac{Q^{i}}{\partial K^{i}} & =r \\
\text { for } i & =A B, A N
\end{aligned}
$$

\footnotetext{
${ }^{3}$ Note that we consider the case where the agricultural commodity suitable for biofuel production may be used for both food and biofuel production. We denote it as biomass to simplify the text.
} 
where $N$ is non-fuel farm input (land), $K$ is fuel farm input, $p$ is output price, $w$ is land rental price, and $r$ is fuel price. $A B$ is index for biomass, and $A N$ is index for food commodity. Equations (1) and (2) are marginal conditions for land and fuel input, respectively, and determine input demand and output supply of agricultural commodities.

In Figure 2 the derived supplies of biomass, $S^{A B}$, and food commodity, $S^{N B}$, are shown as upward sloping curves, panels a and d, respectively. ${ }^{4}$ The aggregate world demand for biomass and food commodity is denoted by $D^{A B}\left(p^{A B}\right)$ and $D^{A B}\left(p^{A B}\right)$, and are shown in panels a and $\mathrm{d}$, respectively. The world supply of land is given by $S^{N}(w)$ (not shown).

We assume constant Leontief transformation technology in biofuel sector with constant extraction coefficient denoted by $\beta$. Each unit of biomass results in $\beta$ units of biofuel. ${ }^{5}$ Additionally, biofuel production yields feed by-product, $\gamma$, units quantity per one unit of biomass. To simplify the analyses, we assume constant value of unit processing costs (adjusted for mark-up), $c$, incurred to biofuel production from one unit of biomass. This implies that biofuel supply, $S^{B}(r)$, and by-product supply, $S^{O}\left(p^{O}\right)$, represent the excess supply of biomass, $S^{A B}-D^{A B}$, adjusted by constant extraction coefficients: $S^{B}=\beta\left(S^{A B}-D^{A B}\right)$ and $S^{O}=\gamma\left(S^{A B}-D^{A B}\right)$, respectively, where $p^{O}$ is the price for by-product. In Figure 2 biofuel supply, $S^{B}$, is shown in panel b.

The world supply of fossil fuel together with biofuel supply generates the aggregate fuel supply curve, $S^{T F}(r)=S^{F}+S^{B}$, where $S^{F}(r)$ is the world supply curve of fossil fuel (panel b in Figure 2). The aggregate fuel demand, $D^{T F}(r)$, is sum of agricultural fuel demand, $K^{A B}+K^{N B}$, and non-agricultural fuel demand, $D^{N F}(r, t)$, where $t$ is an exogenous parameter, which we use to derive the comparative static effects of fuel demand shocks (panel b in Figure 2). In order to simplify the analysis, we assume perfect substitutability between biofuel and fossil fuel in consumption. ${ }^{6}$

The equilibrium conditions for agricultural, input and fuel markets can be summarised in five equilibrium conditions. Food production from biomass, no biofuel

\footnotetext{
${ }^{4}$ In Figure 2 we show biomass market (panel a), fuel market (panel b) and food commodity market (panel d) (by-product and land markets are not shown). The effects sown in Figure 2 take into account adjustments in all markets.

${ }^{5}$ We assume that this coefficient also adjusts for quality differences between biofuel and fossil fuel. Hence it represents biofuel in equivalent of fossil fuel.

${ }^{6}$ In reality, fuel containing low share of biofuels (e.g. $10 \%$ or less in the case of ethanol) can be used in virtually all standard vehicles. However, fuel with high share of biofuels requires engine adaptation, which implies additional (fixed) costs to consumers. Hence, depending on the relative importance of these adjustment costs, the theoretical model may slightly overstate the impact of biofuels on agricultural prices.
} 
production is given by:

$$
\text { if } p_{o}^{A B} \geq \beta r+\gamma p_{o}^{O}-c \Rightarrow S^{B}=S^{O}=0 \Rightarrow D^{A B}=S^{A B}
$$

Food and biofuel production from biomass is given by:

$$
\begin{array}{cl}
\text { if } \quad p_{o}^{A B}<\beta r+\gamma p^{O}-c \Rightarrow S^{B}>0, S^{O}>0 \Rightarrow S^{A B}-D^{A B}>0 \\
\text { and } p^{A B}=\beta r+\gamma p^{O}-c
\end{array}
$$

Food commodity equilibrium:

$$
S^{A N}=D^{A N}
$$

Land market equilibrium:

$$
N^{A B}+N^{A N}=S^{N}
$$

By-product market equilibrium:

$$
S^{O}=D^{O}
$$

Fuel market equilibrium:

$$
S^{T F}=D^{T F}
$$

where $p_{o}^{A B}$ is the equilibrium price for biomass in absence of biofuel production, $p_{o}^{O}$ is by-product price in absence of production of by-product from biomass, and $D^{O}\left(p^{O}\right)$ is by-product demand.

Equation (3) determines the equilibrium condition for biomass. The unit return of biomass, if used to produce biofuels, is given by the adjusted fuel and by-product prices net of processing costs $c: \beta r+\gamma p^{O}-c$. If the return from biofuel is smaller than the biomass equilibrium price prevalent in the absence of biofuel production, $p_{o}^{A B}$, then biofuel production is not profitable in equilibrium. In this case the equilibrium biomass price is determined by intersection of biomass demand and supply, $D^{A B}=S^{A B}$ (equation 3a). The biofuel production occurs in equilibrium, $S^{B}>0$, when the unit return of biomass used for production of biofuels is higher than the biomass price $p_{o}^{A B}$ on the food market: $\beta r+\gamma p^{O}-c>p_{o}^{A B}$. In this case, the equilibrium biomass price is determined by the price for fuel and by-product: $p^{A B}=\beta r+\gamma p^{O}-c$ (equation $3 b$ ). Equation (4) represents the equilibrium condition for food commodity. 
Equations (5) and (6) determine the equilibrium on land and by-product markets, respectively. Equation (7) is clearing condition for the aggregate fuel market equilibrium, where $S^{T F}=S^{F}+S^{B}$ and $D^{T F}=D^{N F}+K^{A B}+K^{A N}$.

Figure 2 shows the equilibrium prices and quantities for biomass market (panel a), fuel market (panel b) and food commodity market (panel d). The equilibrium price and quantity for biomass is $p_{o}^{A B}, Q^{A B}$, and the equilibrium price and quantity for fuel is $r, Q^{F}$. There is no biofuel production in equilibrium, because the return from biomass, if used for biofuel production, would be lower than food price. With fuel price $r$, the unit return of biomass for biofuel production is given by $p^{A B}$ (= $\left.\beta r+\gamma p_{o}^{O}-c\right)$, and the equilibrium food price is $p_{o}^{A B}$. As shown in panel a, $p^{A B}$ is lower than the equilibrium price for biomass, $p^{A B}<p_{o}^{A B}$, implying no biofuel production in equilibrium. ${ }^{7}$ Finally, the equilibrium price and quantity of food commodity is $p^{A N}, Q^{A N}$. We assume that this commodity is used only for food production.

\subsection{Price interdependencies}

In order to understand the channels of price transmission between fuel and agricultural markets, we study the transmission channels graphically and with numerical simulations. We assume Cobb-Douglas production function in agriculture and constant elasticity of substitution functions for supply and demand. We use the world agricultural, biofuel and fuel market data for 2007 to calibrate the model. A detailed overview of the data and their sources is shown in the Appendix. The share of biofuels in the total world fuel production is less than $1 \%$ using approximately $1.6 \%$ of world arable area. The share of agricultural fuel consumption and the share biomass output used for the biofuels is around 3.3\%. To analyse the sensitivity of price transmissions, we simulate two scenarios. First, we assume no biofuel production. In this case, the model is calibrated to world agricultural and fuel data with biofuel data set to zero. Second simulations are performed with biofuel production. ${ }^{8}$

Price transmission may occur in two directions: from fuel to agricultural prices and vice versa. In both directions the transmission of prices may occur through two channels: an indirect input channel and a direct bioenergy channel. First, fuel is used as input in agricultural production. Changes in fuel price will affect agricultural production costs and hence agricultural prices. Similarly, any changes in fuel use in agricultural production affects fuel demand inducing changes in fuel prices. Second, the direct channel of price transmission is effectuated through biofuel demand for

\footnotetext{
${ }^{7}$ Note that the fuel price $r_{o}$ is equivalent to return from the biofuel production at price of biomass $p_{o}^{A B}$. Everything else equal, the biofuel production is profitable for fuel prices higher than $r_{o}$.

${ }^{8}$ As usual, for all scenarios we perform sensitivity analyses by varying model parameters.
} 
agricultural commodities. Fuel price affects the profitability of biofuel production and hence it affects biofuel demand for agricultural commodities. The reverse price transmission from agricultural prices to fuel occurs through the direct channel because agricultural prices affect biofuel profitability, which affects biofuel supply on fuel market.

\subsubsection{The transmission from the fuel price to agricultural prices}

Adjustments on the fuel market have implications for agricultural markets, both on the supply and demand sides. The supply side adjustments include effects such as changes in productivity and technology, changes in oil reserves, etc. The demand side adjustments include, among others, the economic growth and the induced change in energy requirement, changes in consumption patterns (e.g. shift to more fuel-efficient cars), etc.

We start with a situation when oil price is low and biofuel production is not profitable, and later study the demand and supply side channels of price transmission from fuel to agricultural prices by introducing a shock to the non-agricultural fuel demand. In initial equilibrium there is no biofuel production. In this case the price transmission will occur only through the indirect input channel. This situation is shown in Figure 2: the initial equilibrium in the biomass market (panel a), the fuel market (panel b) and the food commodity market (panel d) is $p_{o}^{A B}, Q^{A B} ; r, Q^{F}$; and $p^{A N}, Q^{A N}$, respectively.

A positive shock introduced to the non-agricultural fuel demand shifts the aggregate fuel demand from $D^{T F}$ to $D_{1}^{T F} .9$ The new equilibrium sets are $p_{1 o}^{A B}, Q_{1}^{A B}$; $r_{1}, Q_{1}^{F}$; and $p_{1}^{A N}, Q_{1}^{A N}$, for biomass (panel a), fuel (panel b) and food (panel d), respectively. ${ }^{10}$ Fuel price rises from $r$ to $r_{1}$ leading to higher agricultural production costs, which induces a leftward shift in the supply of agricultural commodities (form $S^{A B}$ to $S_{1}^{A B}$ for biomass and form $S^{A N}$ to $S_{1}^{A N}$ for food commodity). In equilibrium, the prices for both agricultural commodities rise. The price for biomass increases from $p_{o}^{A B}$ to $p_{1 o}^{A B}$. The price for food commodity increases from $p^{A N}$ to $p_{1}^{A N}$.

Consistent with the graphical analysis we report calibrated elasticities in Table 1 using the simulation model (see Appendix for data and model assumptions). Table 1 shows the transmission elasticities of agricultural prices with respect to changes in fuel price, with and without biofuel production (columns 9-12) and for different

\footnotetext{
${ }^{9}$ Note that the aggregate fuel demand is the sum of the non-agricultural fuel demand and the agricultural fuel demand.

${ }^{10}$ Note that these equilibria take into account adjustments in all markets including in by-product and land markets.
} 
values of model parameters (columns 2-8). The price transmission elasticity with no biofuel production is positive for both commodities (columns 9 and 11). Important factors affecting the transmission elasticities are agricultural production parameters, particularly the relative importance of fuel inputs in agricultural production (agricultural production elasticity of fuel). The transmission elasticities of both agricultural commodities in model 1 are equal (0.41), because we assumed the same weight of fuel input in agricultural production for both agricultural commodities (0.30). The price transmission elasticities decline with lower agricultural production elasticity of fuel (columns 9 and 11 in models 7 and 8), because the impact of higher fuel prices on agricultural production costs is smaller when fuel is a relatively less important input in agricultural production. Models 2 and 3 show that the price transmission elasticity decreases in food demand elasticities (columns 9 and 11). This is because the price effect of lower food supply (caused by higher fuel costs) decreases in food demand elasticities. In a special case, when food demand is perfectly elastic, the price for agricultural commodities would not be affected by fuel price. Similarly, the price transmission elasticity decreases with land supply elasticity (model 6). A higher land supply elasticity implies higher availability of land, allowing substitution of land for fuel which partially offsets the fuel cost rise. Note that the price transmission elasticities are almost unaffected by the non-agricultural fuel demand and supply elasticities (columns 9 and 11 in models 4 and 5).

If we consider a further increase in non-agricultural fuel demand, this shifts the aggregate fuel demand further upward to $D_{2}^{T F}$ (Figure 2). This in turn shifts biomass and food supplies to $S_{2}^{A B}$ and $S_{2}^{A N}$, respectively. In Figure 2 the new equilibriums are $p_{2}^{A B}, Q_{2 D}^{A B} ; r_{2}, Q_{2}^{F}$; and $p_{2}^{A N}, Q_{2}^{A N}$, for biomass (panel a), fuel (panel b) and food (panel d), respectively. Note that now the price for fuel is sufficiently high for making biofuel production profitable. The supply of biofuel is given in panel $\mathrm{b},{ }^{11}$ which is determined by the excess supply of biomass adjusted by a constant extraction coefficient: $S_{2}^{B}=\beta\left(S_{2}^{A B}-D^{A B}\right)$. The equilibrium quantity of biofuel is $Q_{2}^{B}=\beta\left(Q_{2 S}^{A B}-Q_{2 D}^{A B}\right)$. Now the price transmission occurs through both the direct biofuel channel and indirect input channel. First, because of higher fuel costs, the supply of both agricultural commodities is reduced. For example, everything else equal, without the production of biofuel, the price for biomass would increase from the initial equilibrium $p_{o}^{A B}$ to $p_{2 o}^{A B}$ (panel a). However, the demand for biofuel pushes the price further up to $p_{2}^{A B}$. This second effect represents the direct biofuel channel of

\footnotetext{
${ }^{11}$ Note that the aggregate fuel supply shifts from $S^{F} S^{F}$ to $S^{F} S_{2}^{T F}$. For fuel prices higher than $r_{2 o}$, the slope of the aggregate fuel supply changes because of biofuels. The horizontal difference between $S_{2}^{T F}$ and $S^{F}$ at fuel price $r_{2}$ is equal to biofuel production: $Q_{2}^{B}=S^{T F}\left(r_{2}\right)-S^{F}\left(r_{2}\right)$.
} 
price transmission. The price for food increases from $p^{A N}$ to $p_{2}^{A N}$, because of higher fuel costs (the indirect channel), and because the use of biomass in biofuel production further increases all input prices and thus further shifts the price for food up (the direct channel). The correlation, $e^{A N}$, between prices for food and fuel is shown in panel c. The correlation is positive implying positive relationship between fuel and food prices. The same holds for biomass (not shown).

In summary, the impact of fuel price on agricultural prices is stronger with than without biofuel production. This is also confirmed by simulation results shown Table 1. Price transmission elasticities are higher in presence of biofuel production (columns 10 and 12) than without biofuel production (columns 9 and 11) for all considered models. With biofuel production (similar to the case of no biofuel production), the price transmission elasticities of both agricultural commodities decrease in food demand elasticities (columns 10 and 12 in models 2 and 3) and in land supply elasticity (model 6), while they increase in the relative importance of fuel in agricultural inputs (models 7 and 8). The price transmission elasticities decrease in non-agricultural fuel demand and supply elasticities (columns 10 and 12 in models 4 and 5).

\subsubsection{The transmission from agricultural prices to fuel price}

Reversely, changes in agricultural markets may induce adjustments in fuel markets. Changes in agricultural markets may concern both the supply side (e.g. weather effect, productivity change due to adoption of new technologies) and demand side (e.g. change in consumption patterns due shifts in preferences, changes in consumption levels due to income growth). Again, the transmission of prices may occur through the direct biofuel channel and/or the indirect input channel. In Figure 3 we show graphically and in Table 2 numerically, the impact of a positive productivity shock to agricultural productivity for both agricultural commodities.

The initial equilibrium on the biomass market (panel a), fuel market (panel b) and food market (panel d) is $p_{o}^{A B}, Q^{A B} ; r, Q^{F}$; and $p^{A N}, Q^{A N}$, respectively. We assume no biofuel production in the initial equilibrium. A positive agricultural productivity shock implies a rightward shift in agricultural commodity supply: the supply of biomass shifts from $S^{A B}$ to $S_{1}^{A B}$ (panel a), and the supply of food shifts from $S^{A N}$ to $S_{1}^{A N}$ (panel d). The impact of agricultural productivity increase on the fuel market depends on how the derived fuel demand in agriculture is affected by the productivity shift. This in turn depends on food demand elasticities.

Inelastic food demand leads to large decline in agricultural commodity prices when agricultural production increases. The productivity gain is offset by decreasing 
output prices, as a result of which, agricultural fuel demand declines. In panel b of Figure 3 the aggregate fuel demand shifts downward from $D^{T F}$ to $D_{1}^{T F} .{ }^{12}$ The new equilibrium on the fuel market is $r_{1}, Q_{1}^{F}$.

We can distinguish between the direct input and the indirect biofuel channels of price transmission, which can be further split into two sub-effects. First, everything else equal, the indirect input channel of price transmission (no biofuel production) reduces the aggregate fuel demand from the initial level $D^{T F}$ to $D_{1}^{T F^{\prime}}$. This aggregate fuel demand shift is driven by decreasing agricultural profitability due to a decrease in biomass and food prices from $p_{o}^{A B}$ to $p_{1 o}^{A B}$ and from $p^{A N}$ to $p_{1}^{A N \prime}$, respectively. ${ }^{13}$ If agriculture would produce only food and no biomass was supplied for biofuel production, the two agricultural output prices would be, $p_{1 o}^{A B}$ and $p_{1}^{A N \prime}$. The direct input channel reduces the price for fuel to $r_{1}^{\prime}$.

Given that $r_{1}^{\prime}>r_{1 o}$, the production of biofuel is profitable. The second, direct biofuel effect, results in a final backward shift in the aggregate fuel demand from $D_{1}^{T F^{\prime}}$ to $D_{1}^{T F}$. Everything else equal, the direct biofuel channel has two effects on fuel price, each moving the price for fuel in opposite directions. First, the effect of biofuels is a rise in fuel price from $r_{1}^{\prime}$ to $r_{1}^{\prime \prime}$, because of more agricultural demand for fuel induced by higher biomass production due to biofuel demand. Second, biofuels reduce fuel price from $r_{1}^{\prime \prime}$ to the equilibrium price $r_{1}$, because biofuels lead to more fuel available on the fuel market, exerting a downward pressure on fuel price. ${ }^{1415}$ The equilibrium equilibrium prices for biomass (panel a) and food (panel d) with inelastic food demands are $p_{1}^{A B}$ and $p_{1}^{A N}$, respectively. The equilibrium biomass price $p_{1}^{A B}$ is determined by biofuel profitability. Food price $p_{1}^{A N}$ is affected by a shift in supply from $S_{1}^{A N \prime}$ to $S_{1}^{A N}$, which is driven by higher agricultural input prices due to biofuel demand of biomass.

Thus, with inelastic food demand, the rise in agricultural productivity reduces fuel price through the indirect input channel (implying positive price transmission

\footnotetext{
${ }^{12}$ Note that the aggregate fuel demand is the sum of agricultural fuel demand and non-agricultural fuel demand. In Figure 3 the shift in the aggregate fuel demand is driven by changes in the agricultural fuel demand.

${ }^{13}$ Given by the shift of agricultural supplies to $S_{1}^{A B}$ and to $S_{1}^{A N \prime}$ in panels b and d of Figure 3, respectively.

${ }^{14}$ Note that if the second effect of biofuel channel is sufficiently high it could reduce the final equilibrium fuel price below or equal to $r_{1}^{\prime}$, with $r_{1}^{\prime \prime}-r_{1} \geq r_{1}^{\prime \prime}-r_{1}^{\prime}$. On the other hand, if the first effect of biofuel channel is sufficiently strong (i.e. if it more than offsets the second effect of biofuel channel and the indirect input channel), then the overall effect of agricultural productivity could lead to higher fuel price than the initial price $r$, which would imply a negative price transmission elasticity.

${ }^{15}$ Note that the aggregate fuel supply without biofuels is given by curve $S^{F} S^{F}$, and with biofuels by curve $S^{F} S_{2}^{T F}$.
} 
elasticity), while the direct biofuel channel may offset, weaken or strengthen the overall effect.

The transmission of prices is different, when the demand for food is elastic. In this case, higher agricultural productivity boosts the agricultural fuel demand, which shifts the aggregate fuel demand upwards. In equilibrium, this corresponds to a shift in the aggregate fuel demand from $D^{T F}$ to $D_{2}^{T F}$ (Figure 3, panel b). The new equilibrium on the fuel market is $r_{2}, Q_{2}^{F}$. Again, we can distinguish between direct and indirect channels of price transmission. Further, the direct channel can be split in two sub-effects.

Everything else equal, the input channel of price transmission shifts the aggregate fuel demand from the initial level $D^{T F}$ to $D_{2}^{T F^{\prime}}$. The increase in the aggregate fuel demand is driven by higher agricultural profitability due to assumed productivity increase, which however is less than offset by decreasing prices for biomass and food from $p_{o}^{A B}$ to $p_{1 o}^{A B}$ and from $p^{A N}$ to $p_{2}^{A N \prime}$, respectively, ${ }^{16}$ in absence of biofuel production. With $D_{2}^{T F^{\prime}}$, the price for fuel is $r_{2}^{\prime}$ implying that the direct input channel has increased the price for fuel.

Everything else equal, the direct biofuel channel shifts the aggregate fuel demand from $D_{2}^{T F F^{\prime}}$ to $D_{2}^{T F}{ }^{17}$ First, biofuels rise the fuel price from $r_{2}^{\prime}$ to $r_{2}^{\prime \prime}$, because of higher agricultural demand for fuel. Second, biofuels reduce fuel price from $r_{2}^{\prime \prime}$ to $r_{2}$, because biofuels increase fuel supply, which exerts a downward pressure on fuel price. ${ }^{18}$ The equilibrium prices for biomass (panel a) and food (panel d) are $p_{2}^{A B}$ and $p_{1}^{A N}$, respectively. The price for biomass, $p_{2}^{A B}$, is determined by biofuel profitability. The price for food, $p_{1}^{A N}$, is determined by a final shift in the supply from $S_{2}^{A N \prime}$ to $S_{1}^{A N}$ (Figure 3). The equilibrium biofuel production equals to $Q_{2}^{B}$. Thus, with elastic food demand, the boost in agricultural productivity leads to a higher fuel price through the indirect input channel (implying negative price transmission elasticity), while the direct biofuel channel may offset, weaken or strengthen the overall effect.

In summary, the total effect of price transmission from agricultural prices to fuel price is ambiguous. The indirect input channel implies positive price transmission elasticity when food demand are inelastic, while negative with elastic food demand. Biofuels may offset, weaken or strengthen the overall effect. Panel c in Figure 3 shows

\footnotetext{
${ }^{16}$ Given by the shift of agricultural supplies to $S_{1}^{A B}$ and to $S_{2}^{A N \prime}$ in panels b and d of Figure 3, respectively.

${ }^{17}$ The fuel demand increases because of higher agricultural demand for fuel induced by biomass production for biofuels.

${ }^{18}$ Note that now the second effect of biofuel channel, $r_{2}^{\prime \prime}-r_{2}$, is higher than the first effect $r_{2}^{\prime \prime}-r_{2}^{\prime}$, so the final equilibrium fuel price, $r_{2}$, is below $r_{2}^{\prime}$. Note that, if the second effect of biofuel channel is sufficiently high $\left(r_{2}^{\prime \prime}-r_{2}>r_{2}^{\prime \prime}-r\right)$, then the overall effect of the productivity increase could reduce fuel price implying a positive transmission elasticity.
} 
the correlation between food and fuel prices. The correlation can be either positive, $e_{1}^{A N}$, or negative, $e_{2}^{A N}$. The same holds for biomass (not shown).

Table 2 summarises the simulation results of price transmission effects from agricultural prices to fuel price. In all models with inelastic food demand for both agricultural commodities (models 1 and 4-8), price transmission elasticities are positive. Agricultural and fuel prices change in the same direction: a positive agricultural productivity shock increases agricultural production and reduces agricultural prices; and lower agricultural prices reduce agricultural fuel demand (the indirect input channel) and make biofuel more profitable (the direct biofuel channel). Both effects exert a downward pressure on fuel price. The price transmission elasticities are lower with than without biofuel production. The price transmission elasticities with biofuel production (columns 10 and 12; models 1 and 4-8) are driven by both direct and indirect channels of price transmission, while without biofuel production (columns 9 and 11; models 1 and 4-8) only by the indirect input channel. However, because the share of biofuel production and the share of agricultural fuel consumption on aggregate fuel are relatively low at around $0.8 \%$ and $3.3 \%$, respectively, the transmission elasticities are relatively small.

The results in Table 2 show that the price transmission elasticities may be negative, if at least one agricultural product has elastic food demand (models 2 and 3). The transmission elasticity is negative, if the demand for food is elastic (columns 9 and 11 ; model 3). ${ }^{19}$ In these models the positive productivity shock rises agricultural production, reduces agricultural prices and increases agricultural fuel demand leading in such a way to higher fuel price (indirect input channel). However, this is the case only when biofuel production is unprofitable (columns 9 and 11; model 3). In contrast, the price transmission elasticity is positive with positive biofuel production (columns 10 and 12; model 3). First, biofuels increase fuel price because of higher agricultural demand for fuel. Second, biofuels increase the aggregate fuel supply exerting a downward pressure on fuel price. The overall effect of direct biofuel channel is a reduction of fuel price which more than offsets the price for fuel rise induced by the indirect input channel. ${ }^{20}$

\footnotetext{
${ }^{19}$ This does not, however, hold in general. When food demands vary in terms of the relative magnitude of elasticities, the price transmission elasticities may be positive or negative depending, among others, on the ratio of elasticities and the relative market sizes between the elastic and inelastic food demands. This can be observed when comparing models 2 and 3 with assumption of no biofuel production (columns 9 and 11). The transmission elasticity is positive in model 2, where the demand for food is elastic, and negative in model 3, where the demand for food is elastic.

${ }^{20}$ However, this does not hold in general. The price transmission elasticity could be positive or negative depending among others on the relative share of agricultural fuel demand and biofuel production in the aggregate fuel consumption.
} 


\section{Cointegration analysis}

\subsection{Econometric approach}

Theoretical findings from the previous section suggest that fossil energy prices affect agricultural commodity prices and, to a lesser extent, agricultural commodity prices affect fossil energy prices. Hence, both fossil energy and agricultural commodity prices are endogenous. In standard regression models the endogeneity of all variables sharply violates the exogeneity assumption, placing particular variables on the right hand side of a regression equation. By specifying a Vector Autoregressive (VAR) model on a system of variables, this problem can be circumvented. In VAR no such conditional factorisation is made before starting. Instead, variables can later be tested for exogeneity, and restricted to be exogenous then. These considerations motivate our choice of the model for studying interdependencies between related price series.

Stationary processes, which have time invariant expected values, variances, and covariances, i.e. the first and second moments of the random variables do not change over time, can be analysed using a simple VAR model. A $m$-variable VAR model of order $n$ can be written as:

$$
P_{t}=\sum_{i=1}^{n} \Gamma_{i} P_{t-i}+\mu+\varepsilon_{t}
$$

where $P$ is a $(M \times 1)$ vector of agricultural and fuel price series at time $t, \Gamma_{i}$ is a $(M \times M)$ matrix of coefficients relating series changes at lagged $i$ period to current changes in series, $\mu$ is a $(M \times 1)$ vector of constants, and $\varepsilon_{t}$ is a $(M \times 1)$ vector of iid errors. According to VAR model (8), each of the $M$ variables is a function of $n$ lags of all $M$ variables, including itself, a constant and a contemporaneous error term.

The estimation of VAR model (8) is subject to several econometric issues. First, in many cases prices series are nonstationary. According to Engle and Granger (1987), if some of the series in $M$ are nonstationary, the VAR in differentiated data will be misspecified, implying that nonstationary processes have to be analysed differently than stationary processes.

Second, according to Engle and Granger, even if each of the variables is nonstationary, a linear combination of them might be stationary. This linear combination is called the cointegrating equation and may be interpreted as a long-run equilibrium relationship among the variables. Controlling for cointegration is necessary, because it affects the specification of the model used for causality testing. If the series are cointegrated, then causality testing should be based on a Vector Error Correction 
model (ECM) rather than an unrestricted VAR model (Johansen 1988; Johansen and Juselius 1990). When cointegration is not modelled, evidence may vary significantly towards detecting causality between the predictor variables. Specifically, the absence of cointegration could mean the violation of the necessary condition for the simple efficiency hypothesis, which implies an absence of a long-run relationship between oil and agricultural commodity prices. Alternatively, based on the underlying conceptual framework (section 2), a failure to find cointegration may be attributed to the nonstationarity of the other components of the underlying relationship between crude oil and agricultural commodity prices, such as the non-fuel input prices in agriculture.

The ECM can be obtained by first differentiating (8) and adding a lagged error term:

$$
\triangle P_{t}=\sum_{i=1}^{k-1} \Gamma_{i} \triangle P_{t-i}+\Pi P_{t-i}+\mu+\varepsilon_{t}
$$

where $P_{t-i}$ is the so called error correction term and $\Pi$ is a $(M \times M)$ coefficient matrix containing response information of lagged levels of random variables to current changes.

Parameters in ECM (9) allow us to identify both the long-run and short-run interdependencies between the $M$ series. The information on long-run relationship between the $M$ variables is summarised in $\Pi$. When the rank of $\Pi$ is a positive number, $r$, and it is less than the number of series, $M$, then $\pi=\alpha \beta$ where $\alpha$ and $\beta$ are $(M \times r)$ matrices. Matrix $\beta$ contains the cointegration parameters, and matrix $\alpha$ includes information on the speed of adjustment. According to Johansen and Juselius (1994) and Johansen (1995), testing the hypothesis on $\beta$ can provide information on long-run structure, while testing the hypothesis on $\alpha$ and $\Gamma_{i}$ can identify the short-run relationships.

Cointegration as such does not say anything about the direction of causality, which however is a central question in out study. For example, one of the oil or agricultural commodities could be a price leader and the others price followers; or, alternatively, none of the commodities might be more important than the others. In the first case, the price of the leading commodity would be driving the prices of the other oil/agricultural commodities (be 'exogenous' to the other prices) and cointegration could be analysed from the equations for the other 'adjusting' prices, given the price of the leader. In the second case, all prices would be 'equilibrium adjusting' and, hence, all equations would contain information about the cointegration relationships. 
In order to identify the direction of causality, we perform Granger causality tests.

\subsection{Data}

Our data consists of weekly price data for crude oil and nine major traded agricultural commodities: corn, wheat, rice, sugar, soybeans, cotton, banana, sorghum and tea for the period 1994-2008. ${ }^{21}$ Crude oil prices are from the Statistics of Norway (19911996) and Energy Information Administration (1997-2009); agricultural output prices are from the Food and Agriculture Organisation (FAO) (see Table 3 in the Appendix for data description and sources). Given that these prices are from markets located in major world trade centres, such as U.S. Gulf (maize, wheat, soybeans) or Bangkok (rice), they represent the world price. All prices are border prices, i.e. free on board (f.o.b.) or cost, insurance and freight (c.i.f.) prices in US dollars (USD).

In order to account for structural changes in the production, demand and policy of oil, bioenergy and agricultural commodities, we divide the price series into three equally sampled periods: $1994-1998,1999-2003$ and 2004-2008. ${ }^{22}$ In each period there are $261 \times 6$ weekly observations, hence $783 \times 6$ observations in total. The segmentation of the sample corresponds roughly to structural breaks. The first break accounts for the reduction in OPEC spare capacity (defined as the difference between sustainable capacity and current OPEC crude oil production). The effect of this event on price dynamics is evident and it can be summarised in the accelerated rise of the average level of oil prices and in the increased volatility. The second break is related to increase in bioenergy policy support and hence production. In May 2003 European Commission adopted directive for promotion of biodiesel. As a result, from 2004 biofuel production increased considerably and it started to gain energy market share. The interdependencies between fuel price and agricultural prices is expected to be stronger in particular in the third period, when biofuel production expanded significantly. Therefore, one may expect that both channels of price transmission are active in the third period, while in the first period only the indirect input channel is likely to exert pressure on agricultural prices.

\subsection{Empirical results}

We start with pretesting the six price series for stationarity and determining lag length. The stationarity is tested using the Augmented Dickey-Fuller (ADF) and

\footnotetext{
${ }^{21}$ The weekly price data for wheat starts from 1998 and for sugar from 1997. For this period monthly sugar price data is used.

${ }^{22}$ A similar approach was followed by Campiche et al (2007).
} 
Phillips Perron tests (PP). Table 4 summarises the ADF test results and Table 5 summarises the PP test results on the level and first differences. In both tests the null hypothesis is a unit root for each variable. Both the ADF and PP tests fail to reject the null hypothesis of unit root suggesting that the levels of all ten prices are nonstationary (Tables 4 and 5, columns 2, 4 and 6). One way how to achieve the stationarity of the prices is to differentiate/detrend the series. Both the ADF and $\mathrm{PP}$ unit root tests of first differences rejects the null of a unit root for the six prices (Tables 4 and 5, columns 3,5 and 7). These results suggest that the five agricultural commodity and crude oil prices in all three periods are integrated of order one, i.e. they are stationary in first differences.

Based on the unit root test results we proceed to determine the lag length, $n$. The most common procedure is to estimate a vector autoregression using the undifferenced data, and then to use the same lag length tests as in a traditional VAR. In STATA we determine the lag length using the Schwarz Information Criterion and Akaike Information Criterion. Both information criterions suggest the optimal lag length of one for all three periods (a maximum of 4 lags was considered).

In a second step, we examine whether there exist cointegrating vectors among the nine agricultural commodity price series and crude oil. We test for cointegration between world market prices for crude oil and each of the nine commodities using the likelihood ratio and trace tests, both of which determine the cointegration rank, $r$. The obtained trace and Max-eigenvalue, $\lambda_{\max }$, statistics of the cointegration rank tests are reported in Tables 6-8. According to Table 6, the Johansen cointegration test results suggest that there are no cointegration relationships in the first period (1994-1998). Both the trace and Max-eigenvalue, $\lambda_{\max }$, statistics of the cointegration rank tests are lower than the critical values at $10 \%$ significance already at the first instance $(r=o)$.

The test results are different for the second period (1999-2003) (Table 7), where both the trace and the likelihood ratio tests reject the absence of cointegration relation between crude oil and corn, and crude oil and soybeans price series at $10 \%$ significance level, which implies the presence of a cointegration relationship between prices for crude oil and corn, and crude oil and soybeans. These results are in line with Campiche et al (2007), who find that corn prices and soybean prices were cointegrated with crude oil prices for the period 2006-2007. For the other seven agricultural commodities (wheat, rice, sugar, cotton, banana, sorghum and tea) both Johansen cointegration tests reject the presence of a cointegrating vector with crude oil. These results are consistent with findings of $Y u$ et al (2006), who examined the relationship between crude oil prices and vegetable oils for biodiesel production (soybean, sun- 
flower, rapeseed and palm oil), and found only one cointegrating vector among the four examined vegetable oil and crude oil prices for the period 1999-2005.

The cointegration test results are even more different for the third period (20042008). According to the likelihood ratio test statistics (Table 8), all nine agricultural commodity prices and crude oil prices contain a cointegrating vector. However, the trace test statistics in Table 8 rejects the presence of a cointegrating vector for rice, cotton and banana prices with crude oil prices at the $10 \%$ significance level. The presence of a cointegration relationship between the crude oil and agricultural commodities prices suggest that these series tend to move towards an equilibrium relationship in the long-run. These results are in line with Hameed and Arshad (2008), who investigate the long-term relationship between the prices for petroleum and vegetable oils prices (palm, soybean, sunflower and rapeseed oil), and also find a long-run equilibrium relationship between the petroleum and palm, soybean, sunflower and rapeseed oil prices.

In general, the results presented in Tables 5-7 are perplexing. A higher significance of the price interdependencies in the third period compared to the first period indicate the presence of the direct biofuel channel of price transmission. The difference in the significance between the two periods can be attributed to the direct biofuel channel. Biofuels expanded in last few years and thus it has likely affected inter-linkages between fuel price and agricultural prices. These results are consistent with the theoretical results shown in tables 1 and 2, where the calibrated elasticities with biofuel production (columns 9 and 11) are higher than without (columns 10 and 12). However, the absence of price interdependencies in the first period (1994-1998) is perplexing. In this period, when the biofuel sector was relatively small and likely had not affected other markets, the fuel price and agricultural prices are expected to be interlinked only through the indirect input channel. The insignificant results indicate that the indirect input channel of price transmission is small and statistically insignificant. This could be due to the fact that we analyse world agricultural prices which are also affected by production in less developed countries. These countries tend to use less fuel based inputs (e.g. machinery, fertilisers), but more labour intensive technologies. This is consistent with the underlying theoretical framework (Table 1, models 7 and 8), where price transmission elasticities decrease in the relative importance of fuel in agricultural inputs employed in agricultural production.

Finally, in order to identify a structural model and determine whether the estimated model is reasonable, we perform innovation accounting and causality tests on the error-correction model of (9). The Granger causality tests suggest long run unidirectional causality from oil price to agricultural commodity prices. However, the tests 
deny the presence of a similar relation in the opposite direction. The coefficients of the error-correction term are highly significant, suggesting that the error-correction term acts as a significant force which causes the integrated variables to return to their long run relation when they deviate from it in all the cases. Furthermore, the magnitudes of the error correction term indicate that it tends to correct the deviation at a low speed. Based on these results we cannot reject the underlying theoretical framework developed in section $2 .^{23}$

The impulse response functions are reported in Figures 4 (impulse oil, response agricultural commodities) and 5 (impulse agricultural commodities, response oil). The impulse response results suggest that all agricultural commodity prices are affected by energy prices, including those that are not directly used for bioenergy production. Second, the impact of a positive oil price shock on agricultural commodities is considerably larger than vice versa. In nominal terms (changes in prices, USD), the largest long-run impact of a positive oil price shock (ca. 26 USD/barrel) is on soybeans prices (ca. $25 \mathrm{USD} /$ tonne) (Figure 4). In value terms the impact is smaller on wheat, corn and rice markets (around $10 \mathrm{USD} /$ tonne). The smallest response is estimated on the tea, banana, cotton, and sugar markets. These results are in line with the underlying conceptual framework (section 2$)^{24}$ and previous studies (Campiche et al 2007, Hameed and Arshad 2008, and Yu et al 2006. The oil price response on agricultural commodity price shocks is insignificant (Figure 5).

The impulse response analysis results allow us to calculate the long run (ca 3 years) price transmission elasticities (Table 9). Generally, the price elasticities of agricultural commodities with respect to oil (top panel) are larger than the elasticities of oil with respect to agricultural commodities (bottom panel). The transmission elasticity of agricultural commodities with respect to oil is strictly positive: fuel price increases agricultural prices of all good. The size of the response depends, among others, on the size of biofuel demand for agricultural commodities and on the relative importance of fuel in agricultural cost input structure. Our findings suggest that the price transmission elasticity is higher for those agricultural goods, which are also used for bioenergy production (sugar, soybeans, corn and wheat). According to the underlying conceptual framework, this may occur due to differences in production technologies between agricultural commodities. The magnitude of our

\footnotetext{
${ }^{23}$ Apart from the conventional linear Granger test we apply a new nonparametric test for nonlinear causality by Diks and Panchenko after controlling for cointegration. In addition to the traditional pairwise analysis, we test for causality while correcting for the effects of the other variables. The results are similar and therefore not reported.

${ }^{24}$ The theoretical elasticities in tables 1 and 2 show relatively high values for the causality from oil price to agricultural commodity prices (table 1) and small values (close to zero) for the causality in reverse direction (table 2).
} 
elasticities ranges between 0.05 and 0.30 and is the same range as in Rahim et al (2008), who estimate the long-run price elasticities for rice and soybeans 0.16 and 0.32 , respectively. However, the estimated elasticities are smaller (Table 9) than theoretically predicted (Table 1). In the theoretical model we assumed perfect market adjustments. In reality, however, market rigidities and market imperfections may reduce or delay price adjustments. ${ }^{25}$ Therefore, the theoretical elasticities in Table 1 can be considered as an upper bound.

The elasticities of oil price with respect to agricultural commodity prices are considerably smaller and for two products (cotton and tea) even negative (bottom panel in Table 9). Several reasons might be responsible for these results. First, because the share of agricultural fuel consumption and the biofuel production is relatively small in the total fuel consumption. Second, because the theoretical impact of agricultural prices on the price of fuel is ambiguous: the causality between agricultural prices and fuel price through both direct and indirect channels of price transmission could be positive or negative (section 2).

\section{Conclusions}

The present paper studies the interdependencies between the energy, bioenergy and food prices. First, we develop a vertically integrated partial equilibrium model to theoretically study the interdependencies between fuel price and agricultural prices. The model is built on the previous work of Gardner (2007) and de Gorter and Just (2008, 2009). We identify two channels of price transmission: direct biofuel channel and indirect input channel. Among others, we show that the impact of fuel price on agricultural prices is stronger with than without biofuel production. Second, we apply time-series analytical mechanisms to nine major traded agricultural commodity prices, including corn, wheat, rice, sugar, soybeans, cotton, banana, sorghum and tea, along with one weighted average world crude oil price for the period 1994-2008. In order to account for structural breaks, we segment the price series into three equally sampled periods: 1994-1998, 1999-2003 and 2004-2008. The main objective is to identify the indirect input channel and the direct biofuel channel of price transmission. The interdependencies between fuel price and agricultural prices is expected to be stronger in particular in the third period due to the expansion biofuels in this period.

Our empirical findings confirm the theoretical hypothesis that energy prices do affect prices for agricultural commodities and the interdependencies between the energy

\footnotetext{
${ }^{25}$ For example, Saitone et al (2008) show that market power in the processing sector may reduce price adjustments on the agricultural markets.
} 
and food markets are increasing over time. Whereas we did not find any cointegration relationships in the first period (1994-1998), in the second period (1999-2003) we found that out of nine agricultural commodity prices only corn, soybeans are cointegrated with crude oil prices. Hence, the co-integration is weaker (less present) than theoretically predicted and indirectly indicates that the indirect input channel of price transmission is small and statistically insignificant. In the third period (2004-2008) we found that the prices for all nine agricultural commodities are cointegrated with crude oil prices indicating the presence of the direct biofuel channel of price transmission. The causality tests suggest that there is a long-run Granger causality from oil to agricultural commodity prices, but not vice versa. Based on the innovation accounting results we calculate the long-run prise transmission elasticities. The impulse response analysis results suggest that all agricultural commodity prices are affected by energy prices, including those that are not directly used for bioenergy production. The impact of a positive oil price shock on agricultural commodities is considerably larger than vice versa. The magnitude of the long-run price transmission elasticities varies between 0.05 and 0.30 (or the fuel price increase by 1 dollar/barrel increases agricultural commodity prices between $0.10 \$$ /tonne and $1.50 \$$ /tonne).

\section{References}

[1] Abler, D. (2001). "Elasticities of Substitution and Factor Supply Elasticities in Canadian, Mexican and United States Agriculture: A Review of Past Studies." In OECD Market Effects of Crop Support Measures. Paris, 57-88.

[2] Amna Awad, A. H. and Fatimah, M. A. (2008). The impact of the petroleum prices on vegetable oil prices: evidence from cointegration test. Proceedings of the 3rd International Borneo Business Conference (IBBC) (2008). P. 504-514.

[3] Aschmann S. (2005). "Energy in Agriculture." ACEEE Forum on Market Transformation Washington, DC March 20, 2005.

[4] Balcombe, K., and A. Prakash (2000). "Estimating the Long-run Supply and Demand for Agricultural Labour in the UK." European Review of Agricultural Economics 27: 153-166.

[5] Benfica R., N. Maximiano, A.M.D. Nucifora and J.T. Thurlow (2008). "Higher Fuel And Food Prices: Impacts and Responses for Mozambique." Agricultural Economics 39(1): 497-511. 
[6] Birur, D., T. Hertel, and W. Tyner (2008). "Impact of Biofuel Production on World Agricultural Markets: A Computable General Equilibrium Analysis," GTAP Working Paper 2413, Purdue University.

[7] Brons, M., P. Nijkamp, E. Pels, and P. Rietveld. (2006). "A Meta-analysis of the Price Elasticity of Gasoline Demand. A System of Equations Approach." Tinbergen Institute Discussion Papers 06-106/3, Tinbergen Institute.

[8] Ciaian, P and D. Kancs (2009a). The Capitalisation of Area Payments into Farmland Rents: Theory and Evidence from the New EU, EERI Research Paper Series 2/2008, the Economics and Econometrics Research Institute, Brussels.

[9] Ciaian, P. and J.F.M. Swinnen (2009). "Credit Market Imperfections and the Distribution of Policy Rents." American Journal of Agricultural Economics Forthcoming in 2009.

[10] Campiche, Jody L., Henry L. Bryant, James W. Richardson, Joe L. Outlaw (2007). Examining the Evolving Correspondence Between Petroleum Prices and Agricultural Commodity Prices, proceeding of the AAEA Meeting, Portland, OR, July 29-August 1, 2007.

[11] de Crombrugghe, D., F.C. Palm, and J. P. Urbain. (1997). "Statistical Demand Functions for Food in the USA and the Netherlands." Journal of Applied Econometrics 12: 615-645.

[12] de Gorter, H. and D. R. Just (2008). "'Water' in the U.S. Ethanol Tax Credit and Mandate: Implications for Rectangular Deadweight Costs and the Corn-Oil Price Relationship." Review of Agricultural Economics 30(3): 397-410.

[13] de Gorter, H. and D. R. Just (2009). "The welfare Economics of a Biofuel Tax Credit and the Interaction Effects with Price Contingent Farm Subsidies." American Journal of Agricultural Economics 91(2): 477-488.

[14] Dickey, D.A., and W.A. Fuller (1981). Likelihood Ratio Statistics for Autoregressive Time Series with a Unit Root. Econometrica 49:1057-1072.

[15] Engle, R. F. \& Granger, C. W. J. (1987). Co-integration and error correction: representation, estimation and testing. Econometrica, (55): 251-276.

[16] European Commission (2008). "Commission's/EU's response to the high oil and food prices." European Commission MEMO/08/421, Brussels. 
[17] FADN (2009). Farm Accountancy Data Network (FADN) data for 2009, European Commission, http://ec.europa.eu/agriculture/rica.

[18] FAO (2008). "Growing Demand on Agriculture and Rising Prices of Commodities; An Opportunity for Smallholders in Low-Income, Agricultural-based Countries?" Proceeding of the Thirty-first session of IFAD's Governing Council, 14 February 2008.

[19] FAO (2009). The State of Food and Agriculture. Food and Agriculture Organization of the United Nations, Rome.

[20] FAOSTAT (2009). http://faostat.fao.org/

[21] Fischer, G. (2008). Implications for Land Use Change. Proceeding of the Expert Meeting on Global Perspectives on Fuel and Food Security, Rome.

[22] Floyd, J.E. (1965). "The Effects of Farm Price Supports on the Return to Land Labour in Agriculture." Journal of Political Economy 73: 148-158.

[23] Gardner, B. (2007). "Fuel Ethanol Subsidies and Farm Price Support." Journal of Agricultural \& Food Industrial Organization 5(2): Article 4.

[24] Greene, D.L., D.W. Jones and P.N. Leiby. (1995). The Outlook for U.S. Oil Dependence, ORNL-6873, Oak Ridge National Laboratory, Oak Ridge.

[25] Hayes, D.J., B.A. Babcock, J.F. Fabiosa, S.Tokgoz, A. Elobeid, T.H.Yu, F. Dong, C.E. Hart, E. Chavez, S. Pan, M. Carriquiry, and J. Dumortier (2009). Biofuels: Potential Production Capacity, Effects on Grain and Livestock Sectors, and Implications for Food Prices and Consumers. CARD Working Paper 09-487, Iowa State University.

[26] Hemery, C. and C. Rizet (2007). "Fuel Price Elasticity of Road Freight Transport Demand in France." COST 355 - WATCH "Changing behaviour towards a more sustainable transport system" Torino 3 October 2007.

[27] Huntington, H.G. (1991). "Inferred Demand and Supply Elasticities from a Comparison of World Oil Models." EMF WP 11.5, The Energy Modeling Forum, Stanford University, Stanford, California, January.

[28] IEA. (2004). Biofuels for Transport: An International Perspective. Paris, OECD/ International Energy Agency.

[29] IEA. (2009). Oil Market Report. International Energy Agency. 
[30] Imai, K., R. Gaiha and G. Thapa (2008). Food and Oil Prices and their Implications for Rural Poverty. Mimeo.

[31] Johansen, S. \& Juselius, K. (1990). Maximum likelihood estimation and inference on cointegration - with applications to the demand for money. Oxford Bulletin of Economics and Statistics, 52: 169-210.

[32] Johansen, S. (1988). Statistical analysis of cointegrating vectors. Journal of Economic Dynamics and Control, 12: 231-254.

[33] Johansen, S. (1991). Estimation and Hypothesis Testing of cointegrating vectors in Gaussian Vector Autoregressive Models. Econometrica 59: 1551-80.

[34] Krichene, N. (2002). World Crude Oil and Natural Gas: A Demand and Supply Model." Energy Economics 24(6): 557-576.

[35] Lipsky, J., (2008). "Commodity Prices and Global Inflation, Remarks At the Council on Foreign Relations." New York City, May 8, 2008.

[36] Lutkepohl, H. and H. Reimers (1992). Impulse Response Analysis of Cointegrated Systems. Journal of Economic Dynamics and Control 16: 53-78.

[37] Mitchell, D. (2008). "A Note on Rising Food Prices" " Policy Research Working Paper 4682, The World Bank, Wasington D.C.

[38] OECD. (2009). OECD-FAO Agricultural Outlook 2009-2018. FAO-OECD.

[39] Pindyck, R.S. (1979).The structure of World Oil Demand." Cambridge: MIT Press.

[40] Rahim A. S., Zariyawati M.A., Mohd Shahwahid H.O. (2008). The relationship between selected Malaysian commodity prices and world crude oil prices, Working Paper, Universiti Putra Malaysia.

[41] Ramcharran, H. (2002). "Oil Production Responses to Price Changes: An Empirical Application of the Competitive Model to OPEC and Non-OPEC Countries." Energy Economics 24(2): 97-106.

[42] Reynolds, D. B. (2002). "Using Non-Time-Series to Determine Supply Elasticity: How Far do Prices Change the Hubbert Curve?" OPEC Review (26) 2: 147-167.

[43] Reuters (2008). "Bad policy, not biofuel, drive food prices: Merkel." Reuters, http://www.reuters.com/article/idUSKRA45973520080424. 
[44] RFA (2008). Feeding the Future: The Role of the U.S. Ethanol Industry in Food and Feed Production. Renewable Fuels Association, Washington, D.C.

[45] Saitone, T.L., R.J. Sexton, and S.E. Sexton (2008). "Market Power in the Corn Sector: How Does It Affect the Impacts of the Ethanol Subsidy." Journal of Agricultural and Resource Economics 33(2): 169-194.

[46] Salhofer, K. (2001). "Elasticities of Substitution and Factor Supply Elasticities in European Agriculture: A Review of Past Studies." In OECD Market Effects of Crop Support Measures. Paris, 89-119.

[47] Schmidhuber, J. (2006). Impact of an Increased Biomass Use on Agricultural Markets, Prices and Food Security: A Longer-Term Perspective, Food and Agriculture Organization of the United Nations, Rome.

[48] Swanson, N.R. and C.W.J. Granger (1997). Impulse Response Functions Based on A Causal Approach to Residual Orthogonalization in Vector Autoregressions. Journal of the American Statistical Association 92: 357-67.

[49] Thijssen, G. (1988). "Estimating a Labour Supply Function of Farm Households." European Review of agricultural Economics 15: 67-78.

[50] Tokgoz S. (2009). "The Impact of Energy Markets on the EU Agricultural Sector." Staff General Research Papers 13024, Iowa State University, Department of Economics.

[51] Tyner, W.E. and F. Taheripour. (2007). "Biofuels, Energy Security, and Global Warming Policy Interactions." proceeding of the National Agricultural Biotechnology Council Conference, 22-24 May 2007, Brookings, SD, USA.

[52] UN (2009). UN National Accounts Main Aggregates Database, http://unstats.un.org/unsd/snaama.

[53] Yu, T.H., Bessler, D. A. and Fuller, S. (2006). Conintegration and causality analysis of world vegetable oil and crude oil prices, proceedings of the AAEA Annual meeting. 


\section{$5 \quad$ Appendix}

\subsection{Model assumptions and parameter values}

The data used to calibrate the model are shown in Table 3. We use two values (upper and lower bound) for each key parameter to analyse the sensitivity of the results. We proxy the share of fuel on total farm costs with the cost share of energy in total agricultural cost structure. The energy cost (e.g. fuel, electricity) share varies significantly across regions. Particularly strong difference is between developed and developing countries. OECD (2000) estimates the cost share of energy for the US equal to 0.08. Based on the calculation from the FADN (2009) the energy cost share varies between 0.04 and 0.13 in EU Member States. The energy also enters indirectly in agriculture particularly through fertilisers and pesticides. OECD (2000) estimates the cost share of fertilisers and chemicals at 0.14 for EU and 0.17 for the US. According to FADN (2009) the share of fertilisers and crop protection inputs varies between 0.03 and 0.14 among EU Member States. We use the parameter equal to 0.15 as lower bound and 0.3 as upper bound in the model.

The most commonly used values for food demand elasticities in the literature vary between -0.1 and -0.7 (e.g. Floyd 1965; de Crombrugghe, Palm, and Urbain 1997; OECD 2000; Ciaian and Swinnen 2009). We use the elasticity -0.5 for the lower bound. The size of the elasticity in terms of whether the food demand is elastic or inelastic has important implication for the results. For this reason the upper value was set to -1.5. For the by-product demand elasticity we assume a value equal to -1.0. We do not perform sensitivity analyses with the by-product demand elasticity.

We use land supply elasticity of 0.2 and 1.5. In empirical studies the land supply elasticity is usually found to be rather low, mostly due to natural constraints. For example, based on an extensive literature review Salhofer (2001) concludes that a plausible range of land supply elasticity for the EU is between 0.1 and 0.4. Similarly, Abler (2001) finds a plausible range between 0.2 and 0.6 for the US, Canada and Mexico. However, FAO (2008) reports a substantial amount of additional land - up to 2 billion hectares - potentially suitable for crop production. Fischer (2008) estimates that between 250 and 800 million hectares are potentially available for expanded crop production after excluding forest land, protected areas and land needed to meet increased demand for food crops and livestock. We use relatively high upper value of the land supply elasticity (1.5) also because the land input is a proxy for all non-fuel inputs in our model. Supply elasticities of non-fuel and non-land inputs vary widely: between 0.1 and 3 (Balcombe and Prakash 2000; Floyd 1965; OECD 2000; Thijssen 1988), because it covers a wide range of inputs (e.g. fertilisers, labour), which have 
various reactions to prices.

We base our assumption regarding the non-agricultural fuel demand elasticity on the studies which estimate the demand elasticity for all sectors in the economy. Studies estimating the elasticity separately for non-agricultural fuel demand are not available. The estimated values lie between -2.0 to 0.3 , but most studies place the this number between -1.0 and 0.0 (e.g. Brons et al. 2006; Hemery and Rizet 2007; Krichene 2002; Greene, Jones and Leiby 1995; Pindyck 1979). We use non-agricultural fuel demand elasticity in the model equal to -0.5 and -1.5 .

The estimates of the fossil fuel supply elasticity vary in the literature between -0.40 and 1.0 (Krichene 2002; Greene, Jones and Leiby 1995; Ramcharran 2002; Reynolds 2002). There is evidence that OPEC countries have negative elasticity explained by the target revenue hypothesis accompanying the backward-bending supply curve, while non-OPEC countries show positive supply elasticity (Ramcharran 2002). In general, the short-run elasticities of fossil fuel demand and supply are very small relative to their long-run elasticity. The long-run fuel market elasticities are about ten times greater than short-run elasticities (Huntington 1991; 1994; Greene, Jones and Leiby 1995; Krichene 2002). We use fossil fuel supply elasticity equal to 0.3 as lower bound and 1.00 as upper bound. 


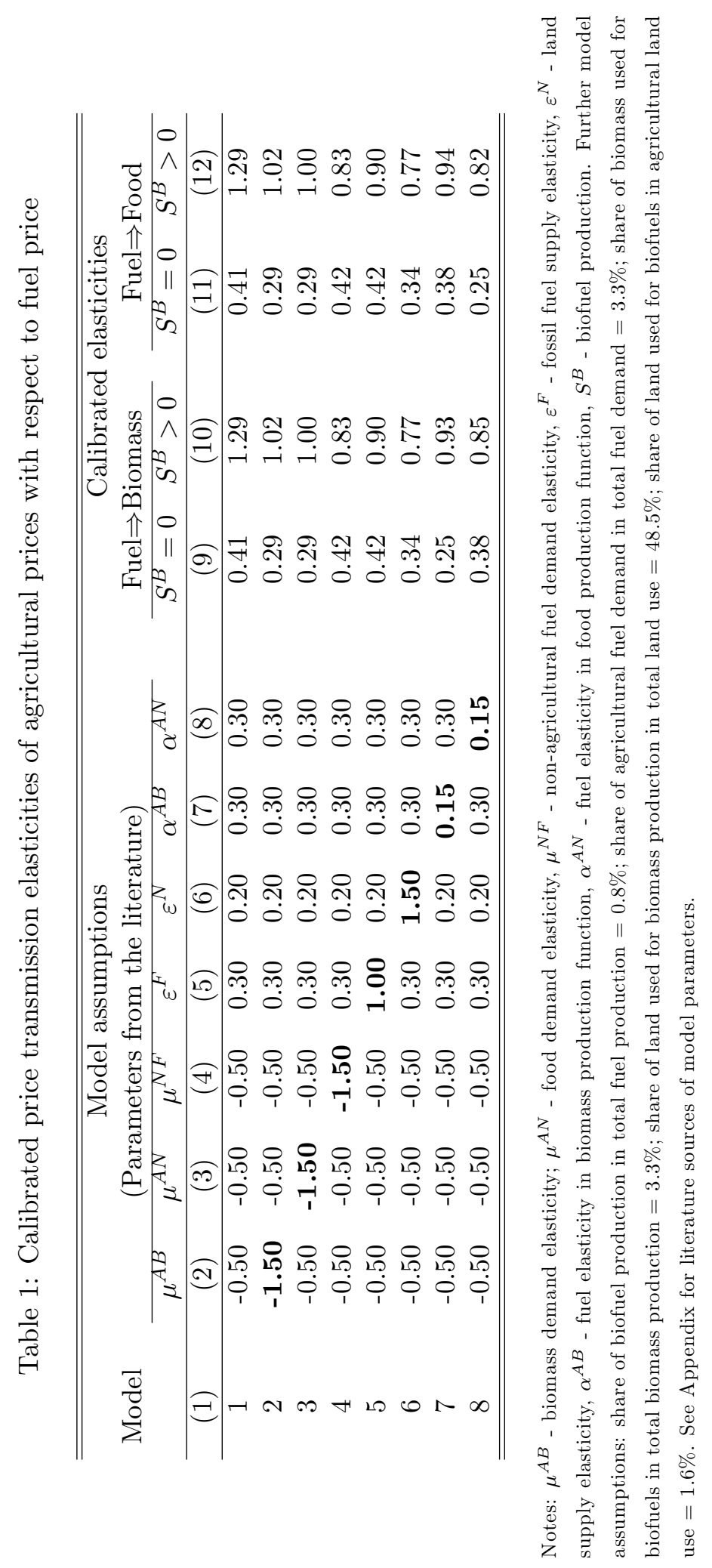




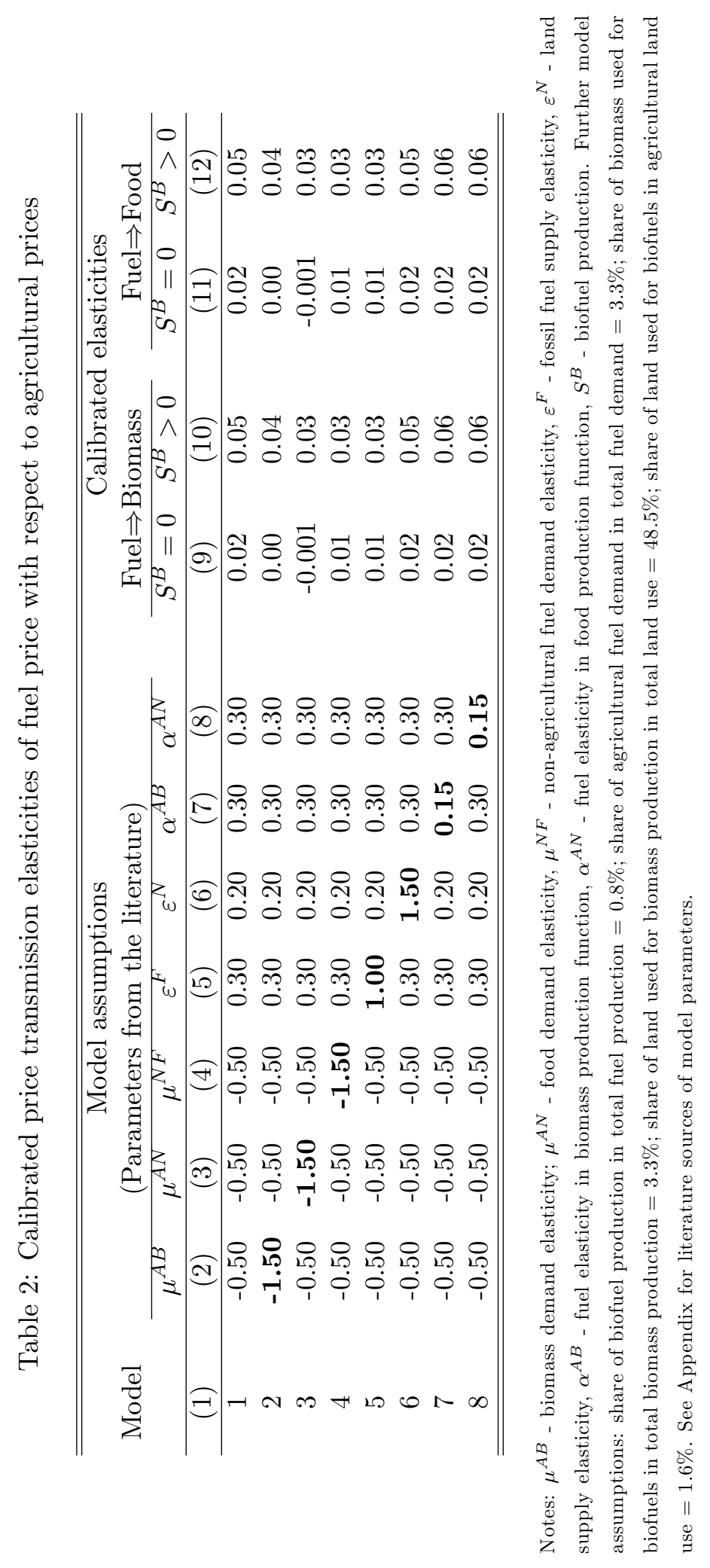




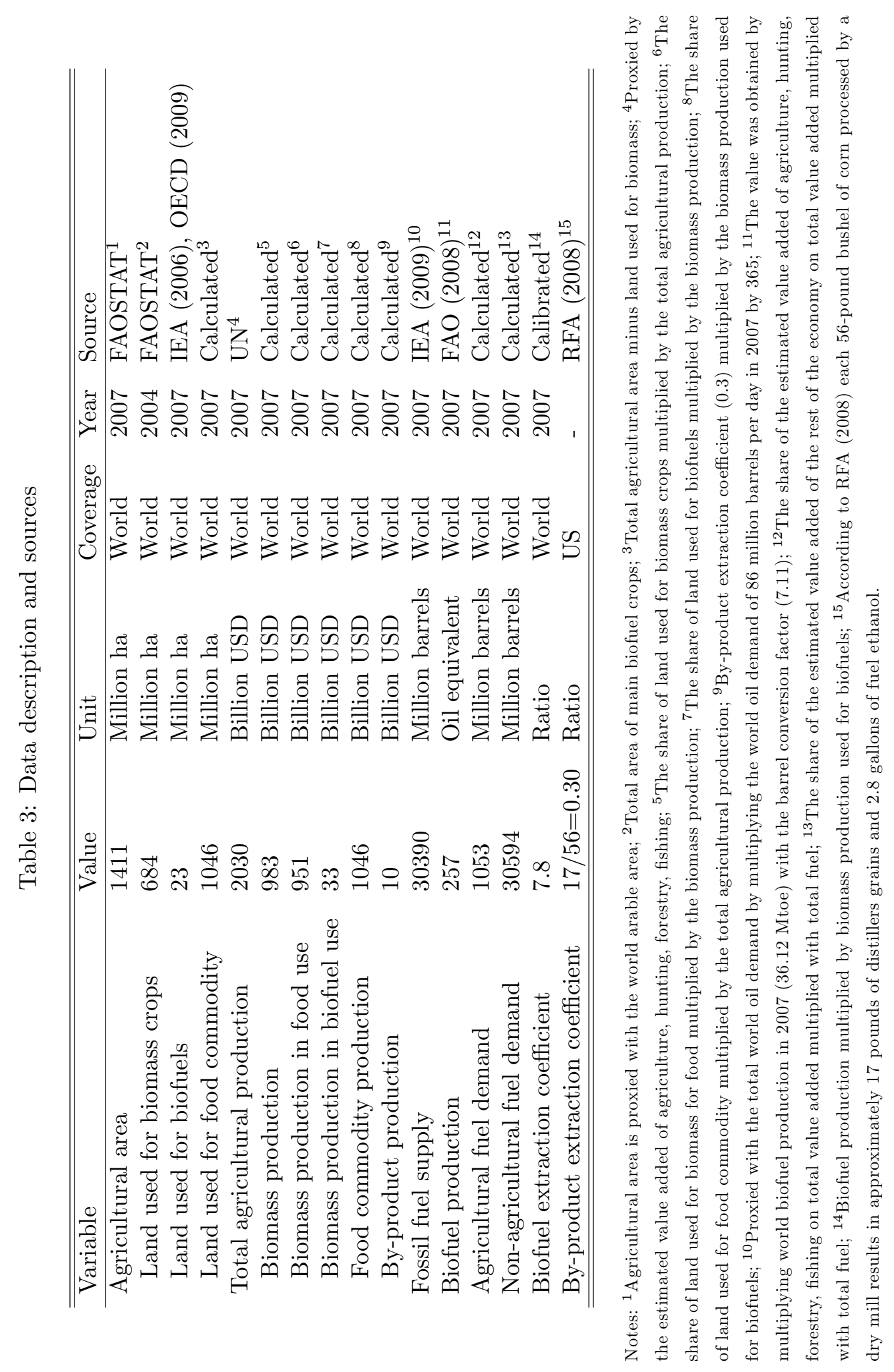


Table 4: ADF unit root test results for prices of crude oil and agricultural commodities

\begin{tabular}{|c|c|c|c|c|c|c|}
\hline \multirow[b]{2}{*}{ Prices } & \multicolumn{2}{|c|}{ 1994-1998 } & \multicolumn{2}{|c|}{ 1999-2003 } & \multicolumn{2}{|c|}{$2004-2008$} \\
\hline & Level & FD & Level & FD & Level & FD \\
\hline Corn & -2.55 & -9.08 †† & -2.16 & $-10.344^{\dagger \dagger}$ & -2.85 & -9.91 ††† \\
\hline Wheat & -2.64 & $-9.56^{\dagger \dagger \dagger}$ & -2.11 & $-8.89 \dagger \dagger \dagger$ & -3.07 & -9.74 †† \\
\hline Rice & -2.35 & $-9.60{ }^{\dagger \dagger \dagger}$ & -2.13 & $-10.43^{\dagger \dagger \dagger}$ & -2.80 & -10.60 †† \\
\hline Sugar & -1.55 & $-9.56^{\dagger \dagger \dagger}$ & -2.81 & $-10.411_{\dagger \dagger}$ & -2.28 & $-9.75 \dagger \dagger \dagger$ \\
\hline Soybeans & -3.02 & $-10.42^{\dagger \dagger \dagger}$ & -2.03 & $-10.200^{\dagger \dagger}$ & -2.21 & $-10.25 \dagger \dagger \dagger$ \\
\hline Cotton & -1.71 & $-9.86^{\dagger \dagger \dagger}$ & -2.95 & $-10.44^{\dagger \dagger \dagger}$ & -2.29 & $-9.97 \dagger \dagger$ \\
\hline Banana & -2.12 & $-9.044^{\dagger \dagger \dagger}$ & -2.33 & $-9.79^{\dagger \dagger \dagger}$ & -3.00 & $-9.83^{\dagger \dagger \dagger}$ \\
\hline Sorghum & -2.39 & $-9.955^{\dagger \dagger \dagger}$ & -1.61 & $-9.97 \dagger^{\dagger \dagger}$ & -2.54 & $-10.96^{\dagger \dagger \dagger}$ \\
\hline Tea & -1.67 & $-9.75 \dagger \dagger \dagger$ & -1.67 & $-9.55 \dagger \dagger \dagger$ & -1.91 & $-9.66^{\dagger \dagger \dagger}$ \\
\hline Crude oil & -1.93 & $-12.66^{\dagger \dagger \dagger}$ & -1.57 & $-15.06^{\dagger \dagger \dagger}$ & -1.56 & $-15.36^{\dagger \dagger \dagger}$ \\
\hline
\end{tabular}

Notes: Augmented Dickey-Fuller test results, ${ }^{\dagger \dagger \dagger}$ significant at $1 \%$ level. Critical Values: $-4.00(1 \%),-3.43$ (5\%), -3.14 (10\%). FD: First Differences.

Table 5: PP unit root test results for prices of crude oil and agricultural commodities

\begin{tabular}{|c|c|c|c|c|c|c|}
\hline \multirow[b]{2}{*}{ Prices } & \multicolumn{2}{|c|}{ 1994-1998 } & \multicolumn{2}{|c|}{ 1999-2003 } & \multicolumn{2}{|c|}{ 2004-2008 } \\
\hline & Level & $\mathrm{FD}$ & Level & FD & Level & FD \\
\hline Corn & -3.06 & $-9.12^{\dagger \dagger \dagger}$ & -2.25 & $-10.98^{\dagger \dagger}$ & -1.95 & $-10.64^{\dagger \dagger \dagger}$ \\
\hline Wheat & -2.65 & $-10.37^{\dagger \dagger \dagger}$ & -2.73 & -10.89 ††† & -2.68 & $-9.31 \dagger^{\dagger \dagger}$ \\
\hline Rice & -1.86 & -10.69 †† & -2.21 & $-8.75 \dagger \dagger \dagger$ & -2.09 & -9.97 †† \\
\hline Sugar & -2.11 & $-10.033^{\dagger \dagger \dagger}$ & -1.52 & $-8.76^{\dagger \dagger \dagger}$ & -1.69 & $-9.30 \dagger \dagger$ \\
\hline Soybeans & -1.51 & $-8.88^{\dagger \dagger \dagger}$ & -1.70 & $-8.97 \dagger \dagger \dagger$ & -2.61 & $-9.71 \dagger \dagger$ \\
\hline Cotton & -2.80 & -9.97 ††† & -3.02 & $-10.57^{\dagger \dagger \dagger}$ & -2.91 & -9.81 †† \\
\hline Banana & -2.06 & $-9.055^{\dagger \dagger \dagger}$ & -1.89 & $-9.52^{\dagger \dagger}$ & -1.74 & -10.62 ††† \\
\hline Sorghum & -3.05 & $-9.55^{\dagger \dagger \dagger}$ & -1.82 & $-10.86 \dagger \dagger \dagger$ & -1.47 & $-10.05 \dagger \dagger \dagger$ \\
\hline Tea & -1.76 & $-10.611^{\dagger \dagger \dagger}$ & -2.16 & $-10.46^{\dagger \dagger \dagger}$ & -1.76 & $-9.14 \dagger \dagger \dagger$ \\
\hline Crude oil & -2.35 & $-10.88^{\dagger \dagger \dagger}$ & -2.31 & $-12.955^{\dagger \dagger \dagger}$ & -1.45 & $-13.944^{\dagger \dagger \dagger}$ \\
\hline
\end{tabular}

Notes: Phillips Perron test results, ${ }^{\dagger \dagger}$ significant at $1 \%$ level. Critical Values: $-4.10(1 \%),-3.43(5 \%),-3.17$ (10\%). FD: First Differences. 
Table 6: Johansen cointegration test results for crude oil and food prices, 1994 - 1998

\begin{tabular}{|c|c|c|c|c|c|c|}
\hline & \multicolumn{4}{|c|}{ L-max Test } & \multicolumn{2}{|c|}{ Trace Test } \\
\hline & $H_{o}:$ & $r=0$ & $r=1$ & $H_{O}:$ & $r=0$ & $r=1$ \\
\hline \multirow[t]{2}{*}{ Corn - crude oil } & & $4.70^{\dagger}$ & 2.56 & & $6.46^{\dagger}$ & 2.05 \\
\hline & & $(0.051)$ & $(0.006)$ & & $(0.037)$ & $(0.005)$ \\
\hline \multirow[t]{2}{*}{ Wheat - crude oil } & & $4.13^{\dagger}$ & 2.08 & & $5.72^{\dagger}$ & 1.67 \\
\hline & & $(0.010)$ & $(0.010)$ & & $(0.071)$ & $(0.011)$ \\
\hline \multirow[t]{2}{*}{ Rice - crude oil } & & $7.02^{\dagger}$ & 1.44 & & $7.10^{\dagger}$ & 2.37 \\
\hline & & $(0.020)$ & $(0.015)$ & & $(0.118)$ & $(0.010)$ \\
\hline \multirow[t]{2}{*}{ Sugar - crude oil } & & $4.41^{\dagger}$ & 2.03 & & $6.15^{\dagger}$ & 2.17 \\
\hline & & $(0.035)$ & $(0.009)$ & & $(0.055)$ & $(0.009)$ \\
\hline \multirow[t]{2}{*}{ Soybeans - crude oil } & & $7.02^{\dagger}$ & 1.48 & & $5.98^{\dagger}$ & 1.42 \\
\hline & & $(0.035)$ & $(0.006)$ & & $(0.025)$ & $(0.005)$ \\
\hline \multirow[t]{2}{*}{ Cotton - crude oil } & & $7.04^{\dagger}$ & 2.05 & & $7.54^{\dagger}$ & 2.58 \\
\hline & & $(0.020)$ & $(0.005)$ & & $(0.059)$ & $(0.009)$ \\
\hline \multirow[t]{2}{*}{ Banana - crude oil } & & $6.33^{\dagger}$ & 2.72 & & $6.01^{\dagger}$ & 2.80 \\
\hline & & $(0.023)$ & $(0.013)$ & & $(0.050)$ & $(0.009)$ \\
\hline \multirow[t]{2}{*}{ Sorghum - crude oil } & & $5.42^{\dagger}$ & 1.59 & & $8.58^{\dagger}$ & 1.82 \\
\hline & & $(0.017)$ & $(0.008)$ & & $(0.023)$ & $(0.006)$ \\
\hline \multirow[t]{2}{*}{ Tea - crude oil } & & $5.91^{\dagger}$ & 1.73 & & $6.44^{\dagger}$ & 1.62 \\
\hline & & $(0.035)$ & (0.006) & & (0.019) & $(0.004)$ \\
\hline
\end{tabular}

Notes: Johansen $(1988,1991)$ L-max and Trace test statistics. $r=0$ - no cointegration relationship; $r=1$ - at most one cointegration relationship. Critical values at $10 \%$ significance level are $10.60(\mathrm{r}=0)$ and $2.71(\mathrm{r}=1)$ for the L-max test and $13.31(\mathrm{r}=0)$ and $2.71(\mathrm{r}=1)$ for the Trace test. Asymptotic significance level ( $p$-values) in parenthesis. ${ }^{\dagger}$ denotes failure to reject the hypothesis at the $10 \%$ level. 
Table 7: Johansen cointegration test results for crude oil and food prices, 1999 - 2003

\begin{tabular}{|c|c|c|c|c|c|c|}
\hline & \multicolumn{4}{|c|}{ L-max Test } & \multicolumn{2}{|c|}{ Trace Test } \\
\hline & $H_{o}:$ & $r=0$ & $r=1$ & $H_{O}:$ & $r=0$ & $r=1$ \\
\hline \multirow[t]{2}{*}{ Corn - crude oil } & & 12.78 & $1.41^{\dagger}$ & & 14.13 & $1.76^{\dagger}$ \\
\hline & & $(0.060)$ & $(0.014)$ & & $(0.038)$ & $(0.004)$ \\
\hline \multirow[t]{2}{*}{ Wheat - crude oil } & & $7.40^{\dagger}$ & 2.25 & & $6.17^{\dagger}$ & 1.45 \\
\hline & & $(0.019)$ & $(0.005)$ & & $(0.015)$ & $(0.009)$ \\
\hline \multirow[t]{2}{*}{ Rice - crude oil } & & $6.31^{\dagger}$ & 2.01 & & $6.58^{\dagger}$ & 1.64 \\
\hline & & $(0.025)$ & $(0.011)$ & & $(0.016)$ & $(0.025)$ \\
\hline \multirow[t]{2}{*}{ Sugar - crude oil } & & $7.26^{\dagger}$ & 1.94 & & $6.17^{\dagger}$ & 2.34 \\
\hline & & $(0.034)$ & $(0.019)$ & & $(0.018)$ & $(0.028)$ \\
\hline \multirow[t]{2}{*}{ Soybeans - crude oil } & & 12.50 & $2.05^{\dagger}$ & & 13.51 & $2.39^{\dagger}$ \\
\hline & & $(0.070)$ & $(0.006)$ & & $(0.040)$ & $(0.013)$ \\
\hline \multirow[t]{2}{*}{ Cotton - crude oil } & & $7.85^{\dagger}$ & 2.29 & & $6.18^{\dagger}$ & 1.89 \\
\hline & & $(0.080)$ & $(0.008)$ & & $(0.030)$ & $(0.005)$ \\
\hline \multirow[t]{2}{*}{ Banana - crude oil } & & $7.16^{\dagger}$ & 1.56 & & $7.07^{\dagger}$ & 1.46 \\
\hline & & $(0.024)$ & $(0.019)$ & & $(0.027)$ & $(0.017)$ \\
\hline \multirow[t]{2}{*}{ Sorghum - crude oil } & & $5.88^{\dagger}$ & 1.80 & & $6.75^{\dagger}$ & 2.17 \\
\hline & & $(0.022)$ & $(0.011)$ & & $(0.101)$ & $(0.043)$ \\
\hline \multirow[t]{2}{*}{ Tea - crude oil } & & $5.92^{\dagger}$ & 1.92 & & $7.15^{\dagger}$ & 2.27 \\
\hline & & $(0.015)$ & (0.006) & & $(0.083)$ & $(0.014)$ \\
\hline
\end{tabular}

Notes: Johansen $(1988,1991)$ L-max and Trace test statistics. $r=0$ - no cointegration relationship; $r=1$ - at most one cointegration relationship. Critical values at $10 \%$ significance level are $10.60(\mathrm{r}=0)$ and $2.71(\mathrm{r}=1)$ for the L-max test and $13.31(\mathrm{r}=0)$ and $2.71(\mathrm{r}=1)$ for the Trace test. Asymptotic significance level ( $p$-values) in parenthesis. ${ }^{\dagger}$ denotes failure to reject the hypothesis at the $10 \%$ level. 
Table 8: Johansen cointegration test results for crude oil and food prices, 2004 - 2008

\begin{tabular}{|c|c|c|c|c|c|c|}
\hline & \multicolumn{4}{|c|}{ L-max Test } & \multicolumn{2}{|c|}{ Trace Test } \\
\hline & $H_{o}:$ & $r=0$ & $r=1$ & $H_{o}:$ & $r=0$ & $r=1$ \\
\hline \multirow[t]{2}{*}{ Corn - crude oil } & & 16.03 & $1.43^{\dagger}$ & & 16.21 & $1.63^{\dagger}$ \\
\hline & & $(0.056)$ & $(0.004)$ & & $(0.040)$ & $(0.005)$ \\
\hline \multirow[t]{2}{*}{ Wheat - crude oil } & & 15.44 & $1.62^{\dagger}$ & & 14.31 & $1.82^{\dagger}$ \\
\hline & & $(0.039)$ & $(0.008)$ & & $(0.064)$ & $(0.007)$ \\
\hline \multirow[t]{2}{*}{ Rice - crude oil } & & 13.18 & $1.29^{\dagger}$ & & $13.09^{\dagger}$ & 1.62 \\
\hline & & $(0.055)$ & $(0.005)$ & & $(0.040)$ & $(0.008)$ \\
\hline \multirow[t]{2}{*}{ Sugar - crude oil } & & 14.52 & $1.44^{\dagger}$ & & 15.71 & $1.57^{\dagger}$ \\
\hline & & $(0.094)$ & $(0.004)$ & & $(0.047)$ & $(0.004)$ \\
\hline \multirow[t]{2}{*}{ Soybeans - crude oil } & & 14.60 & $1.92^{\dagger}$ & & 15.96 & $1.17^{\dagger}$ \\
\hline & & $(0.071)$ & (0.027) & & (0.039) & $(0.004)$ \\
\hline \multirow[t]{2}{*}{ Cotton - crude oil } & & 12.18 & $1.90^{\dagger}$ & & $12.99^{\dagger}$ & 1.37 \\
\hline & & $(0.078)$ & $(0.033)$ & & $(0.180)$ & $(0.016)$ \\
\hline \multirow[t]{2}{*}{ Banana - crude oil } & & 12.75 & $1.00^{\dagger}$ & & $12.92^{\dagger}$ & 1.69 \\
\hline & & $(0.107)$ & $(0.003)$ & & $(0.034)$ & $(0.008)$ \\
\hline \multirow[t]{2}{*}{ Sorghum - crude oil } & & 12.35 & $1.22^{\dagger}$ & & 13.93 & $1.64^{\dagger}$ \\
\hline & & $(0.060)$ & $(0.022)$ & & $(0.125)$ & $(0.011)$ \\
\hline \multirow[t]{2}{*}{ Tea - crude oil } & & 12.01 & $1.47^{\dagger}$ & & 13.74 & $1.60^{\dagger}$ \\
\hline & & $(0.054)$ & (0.011) & & (0.138) & (0.008) \\
\hline
\end{tabular}

Notes: Johansen $(1988,1991)$ L-max and Trace test statistics. $r=0$ - no cointegration relationship; $r=1$ - at most one cointegration relationship. Critical values at $10 \%$ significance level are $10.60(\mathrm{r}=0)$ and $2.71(\mathrm{r}=1)$ for the L-max test and $13.31(\mathrm{r}=0)$ and $2.71(\mathrm{r}=1)$ for the Trace test. Asymptotic significance level ( $p$-values) in parenthesis. ${ }^{\dagger}$ denotes failure to reject the hypothesis at the $10 \%$ level. 


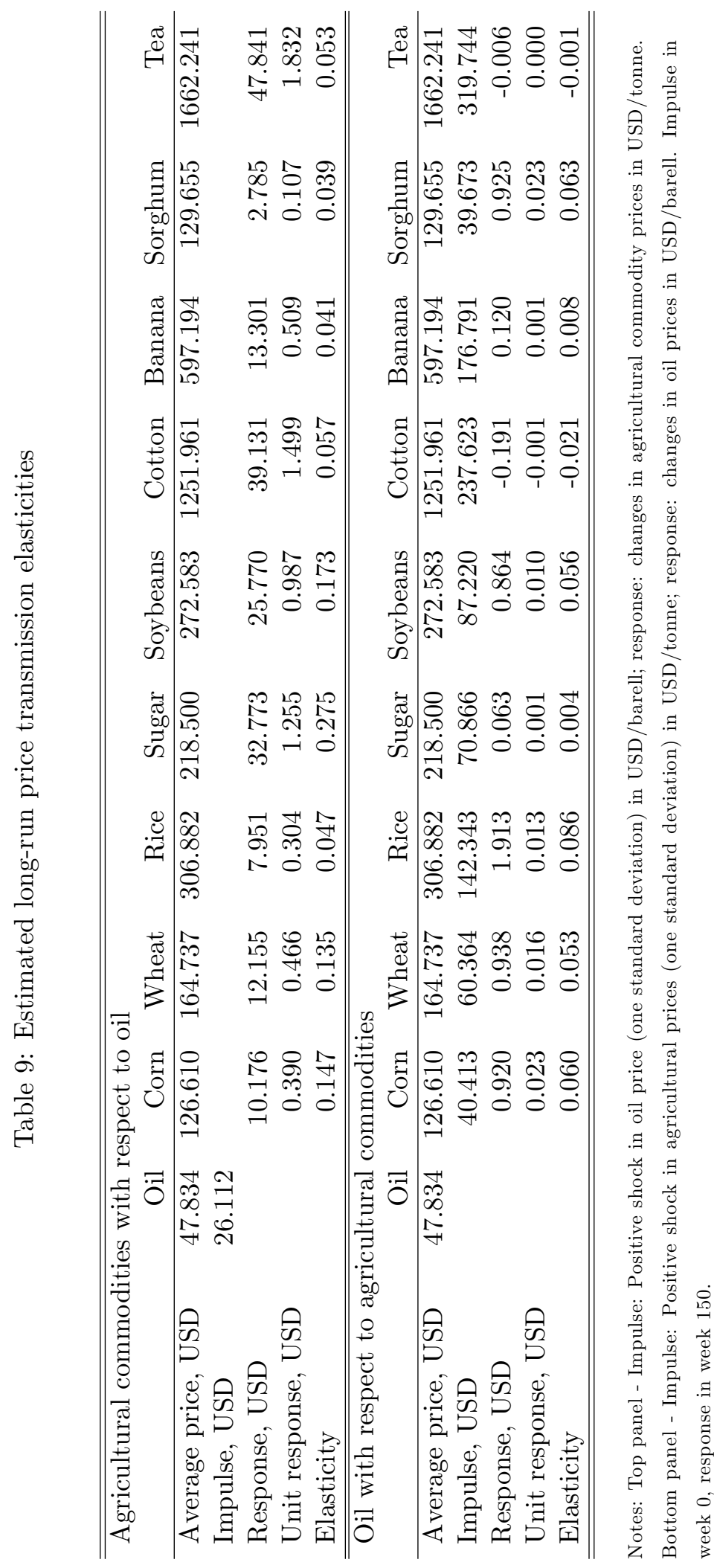




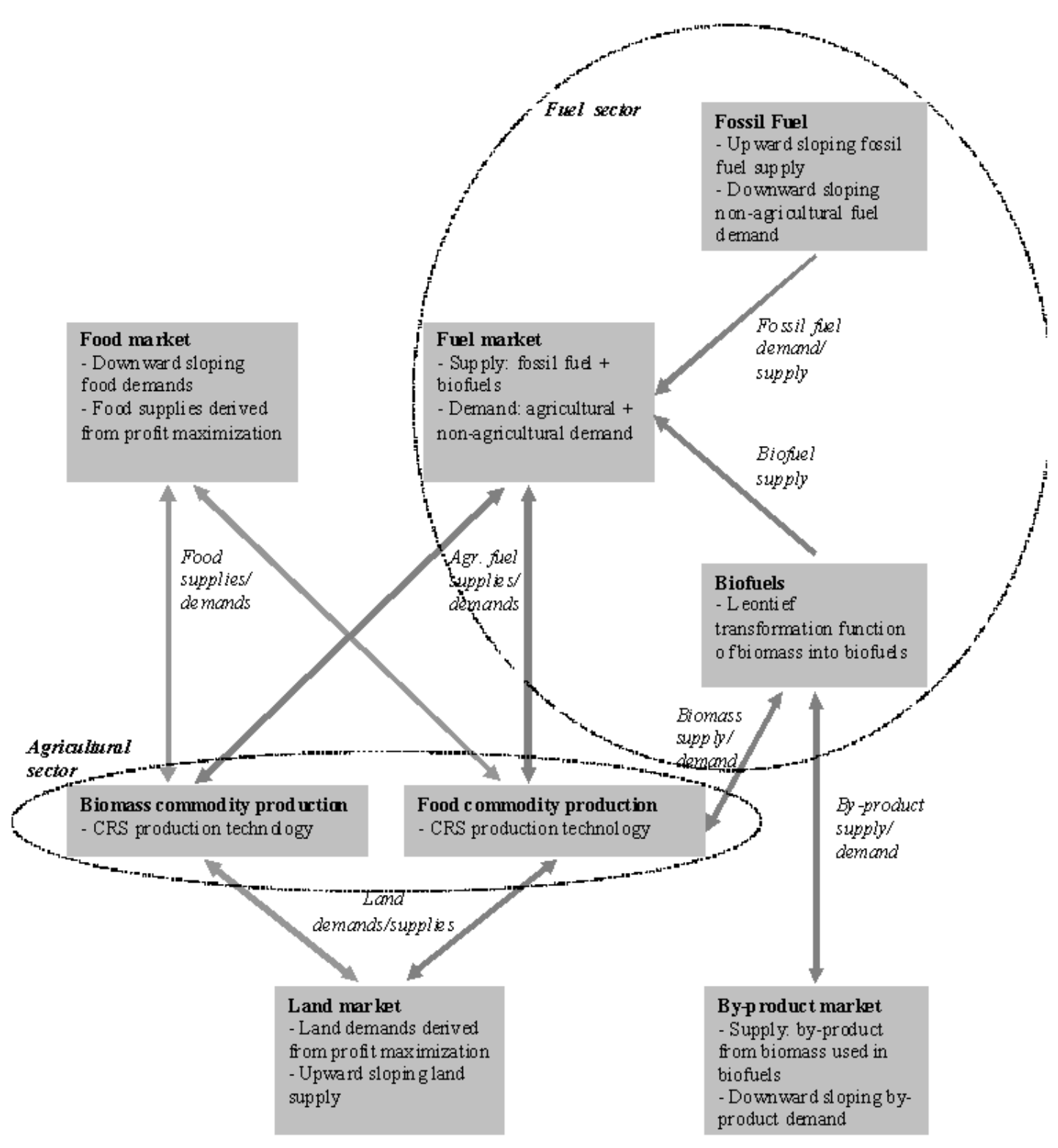

Figure 1: The structure of the model 
(a) Biom ass $M$ arket

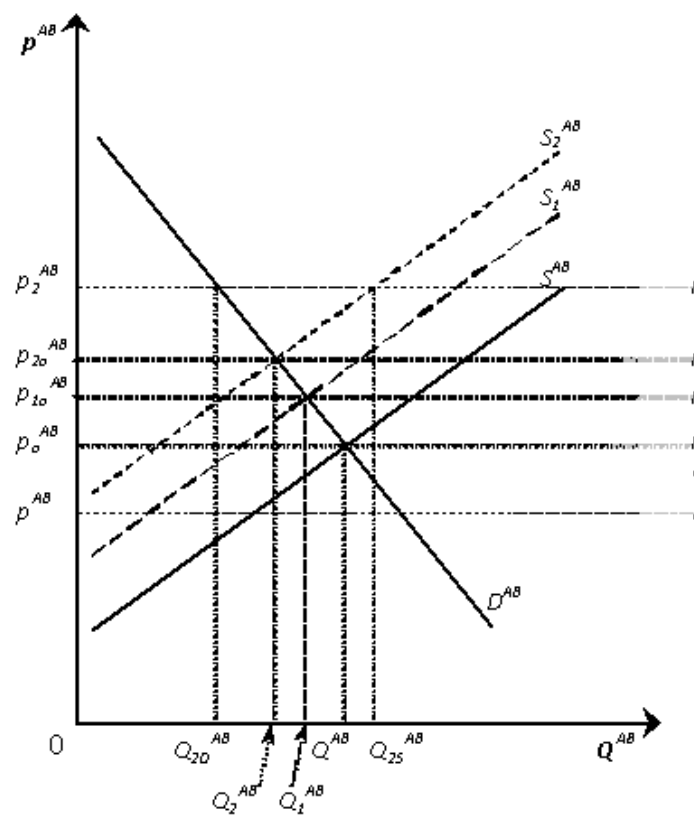

(c) Elasticity bet ween price of food

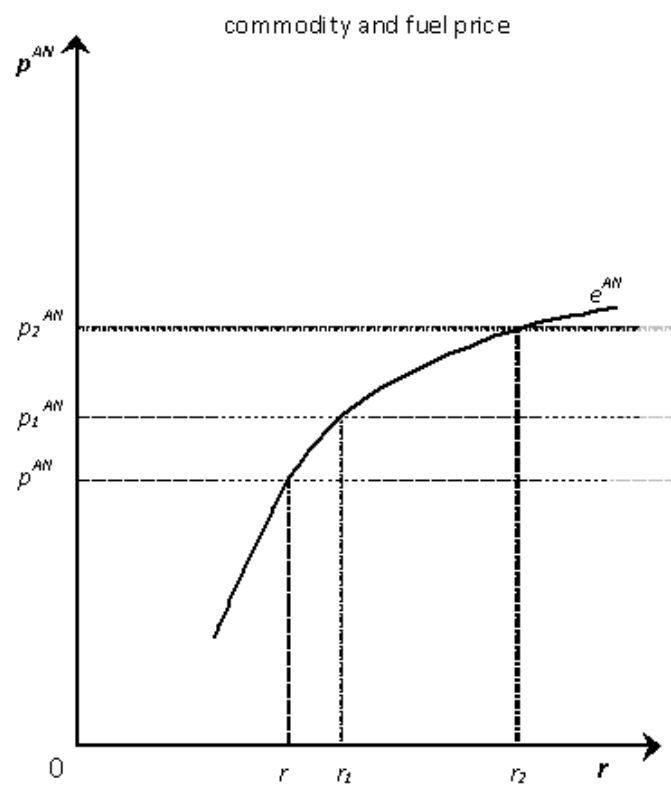

(b) Fuel Market

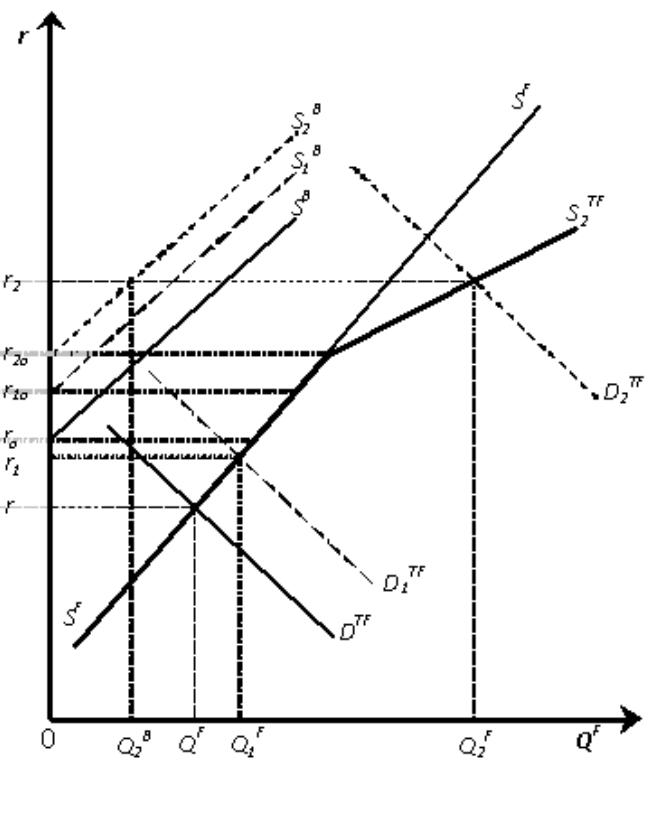

(d) Food comm odity market

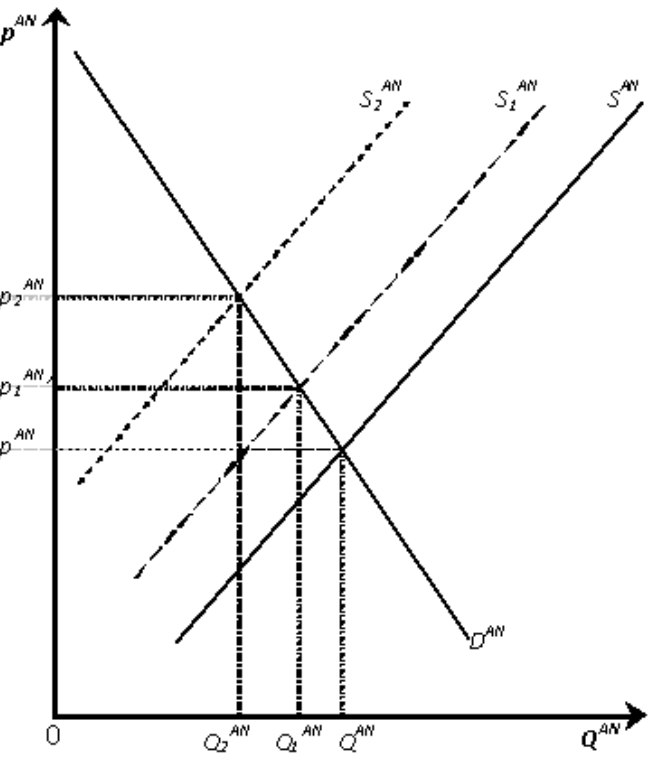

Figure 2: The effect of the non-agricultural fuel demand expansion 
(a) Biom ass Market

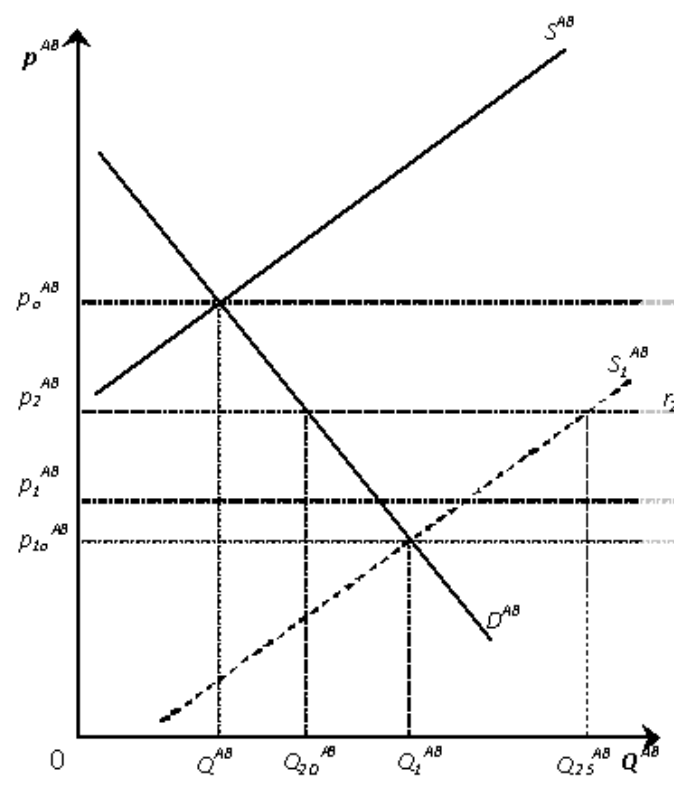

(c) Elasticity bet ween price of food

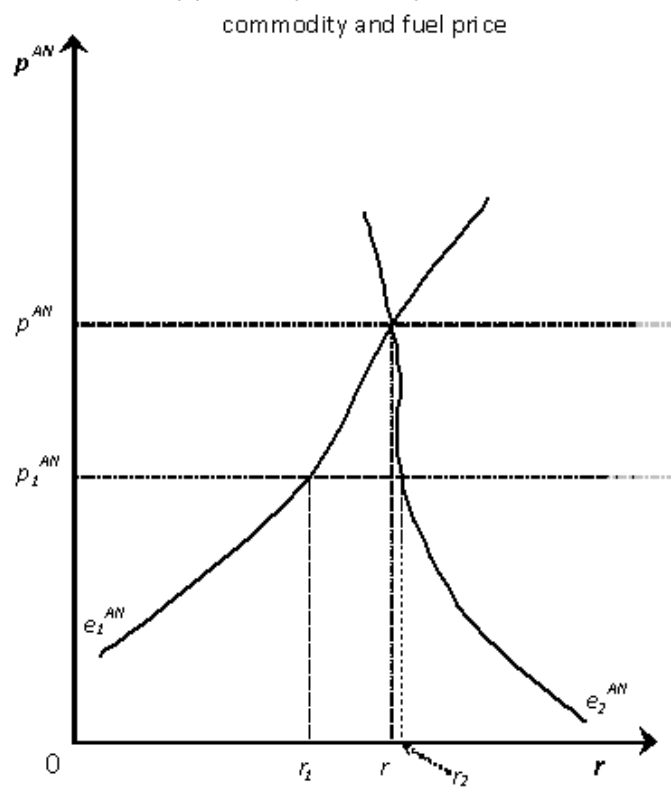

(b) Fuel M arket

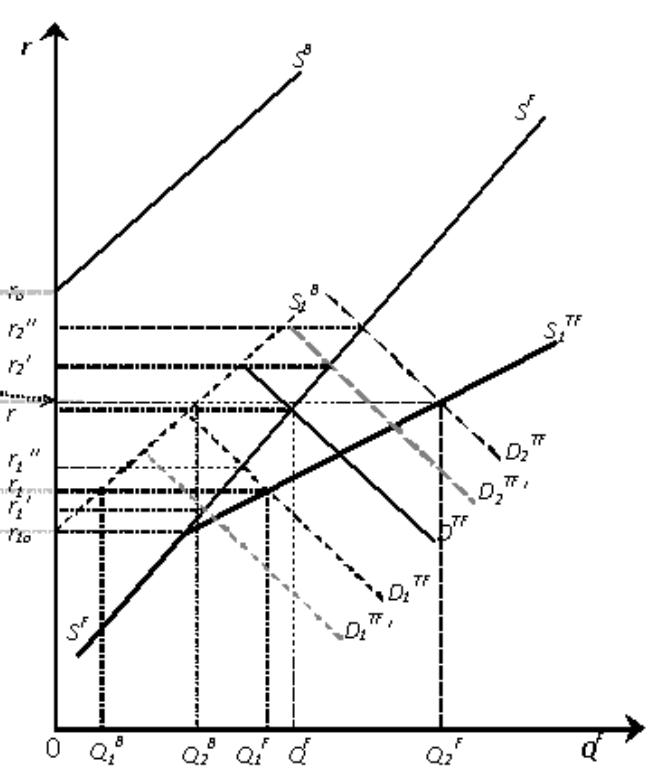

(d) Food commodity market

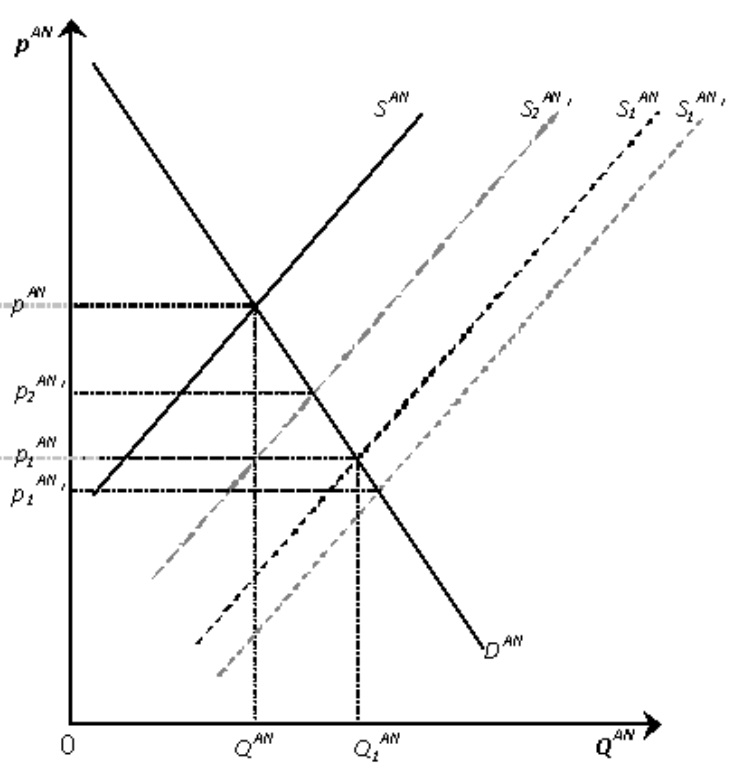

Figure 3: The effect of a positive agricultural production shock 


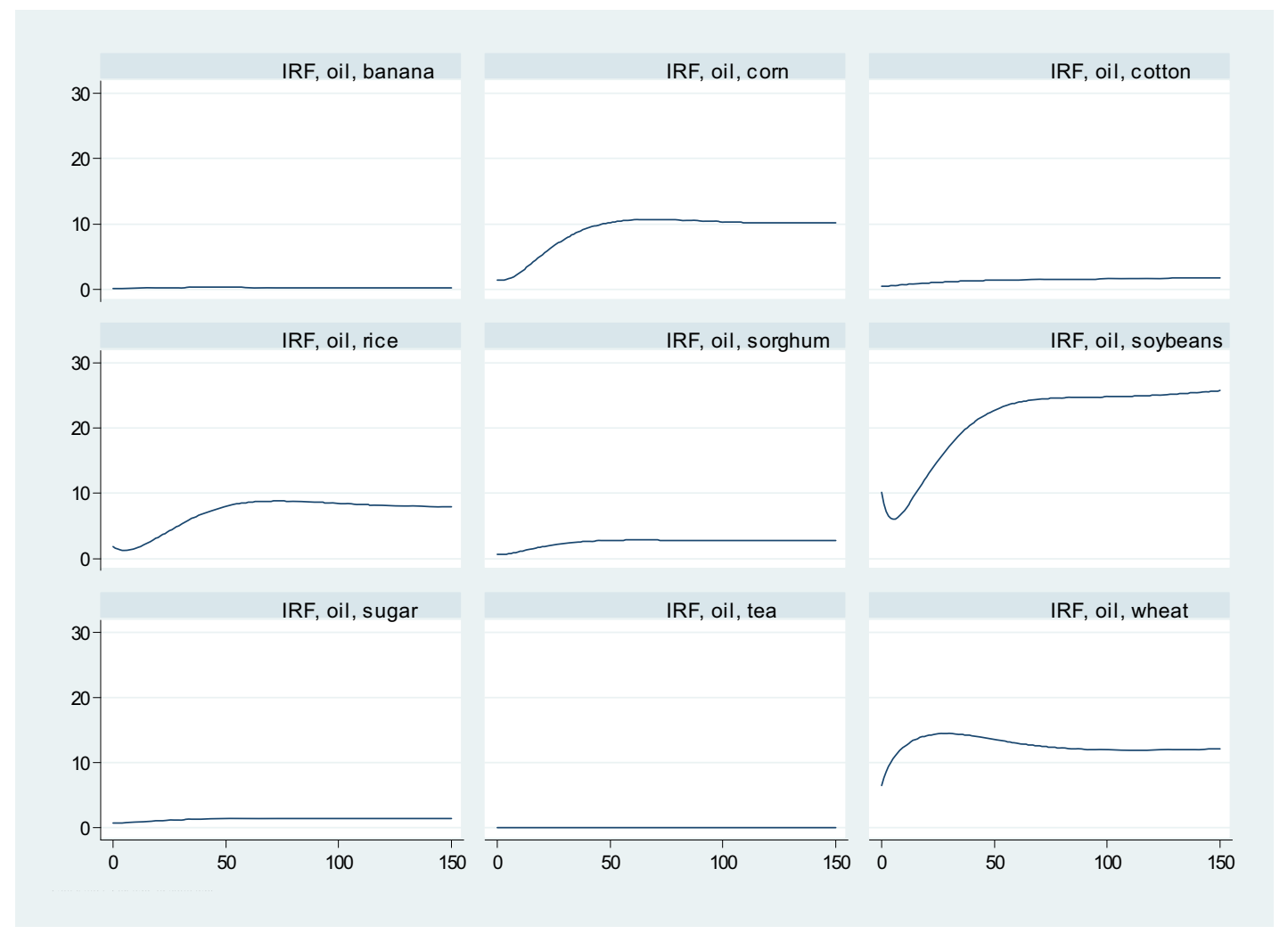

Figure 4: Impulse response function (IRF) by agricultural commodity. Notes: Impulse: positive oil price shock (1 STD) in USD; response: changes in commodity prices over 150 weeks in USD 


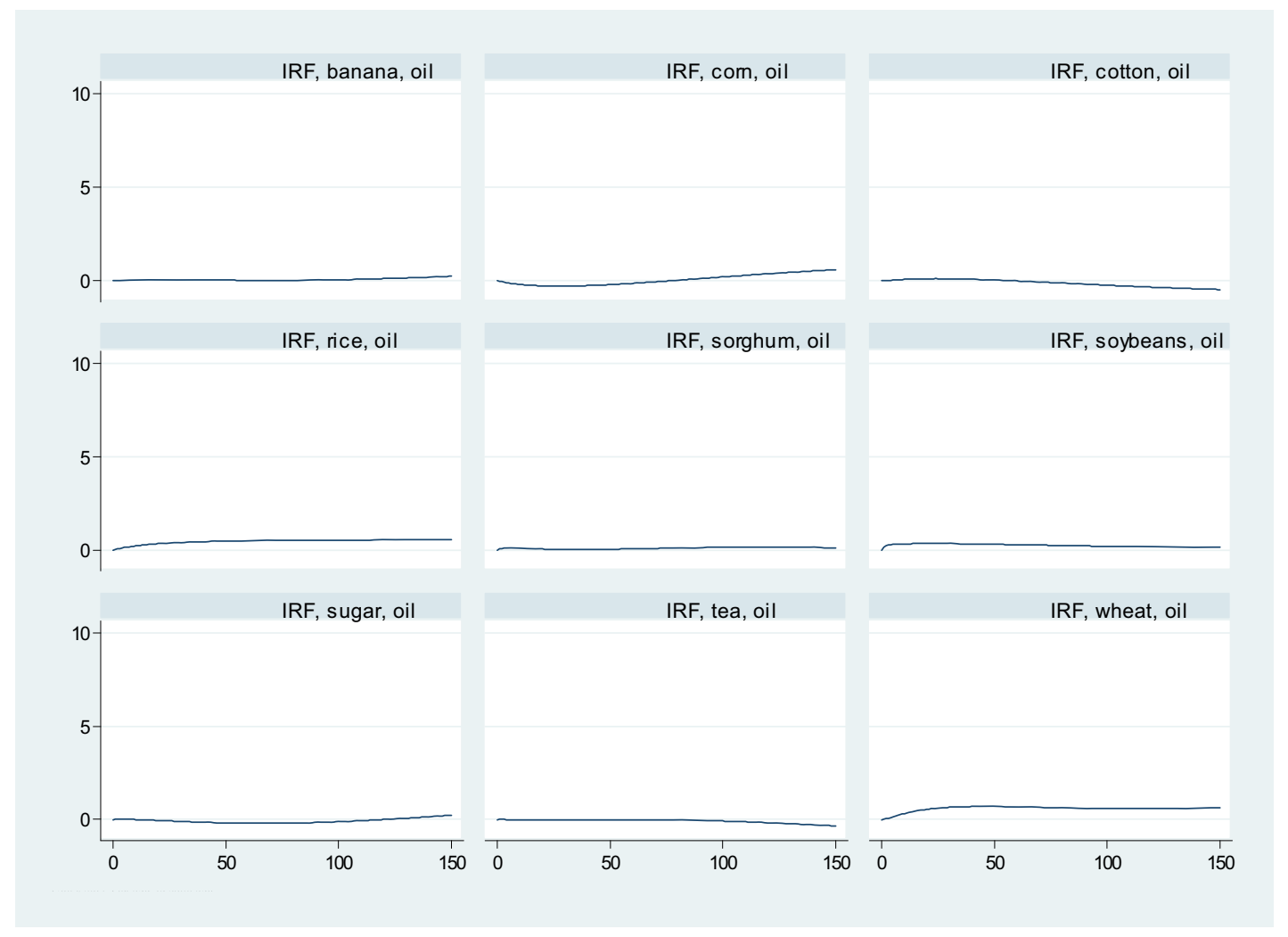

Figure 5: Impulse response function (IRF) by agricultural commodity. Notes: Impulse: positive agricultural price shock (1 STD) in USD; response: changes in oil prices over 150 weeks in USD 